\title{
A Systematic Review of Reliability Studies on Composite Power Systems: A Coherent Taxonomy Motivations, Open Challenges, Recommendations, and New Research Directions
}

\author{
Hamza Abunima ${ }^{1}$, Jiashen Teh ${ }^{1, *(\mathbb{D}}$, Ching-Ming Lai ${ }^{2}{ }^{2}$ and Hussein Jumma Jabir ${ }^{1,3}(\mathbb{C}$ \\ 1 School of Electrical and Electronic Engineering, Universiti Sains Malaysia, \\ Nibong Tebal 14300, Penang, Malaysia; habunima@gmail.com (H.A.); hjjahmn@gmail.com (H.J.J.) \\ 2 Department of Vehicle Engineering, National Taipei University of Technology, 1, Sec. 3, \\ Chung-Hsiao E. Road, Taipei 10608, Taiwan; pecmlai@gmail.com \\ 3 Inspector General Office, Ministry of Water Resources, Filastin 10046, Baghdad, Iraq \\ * Correspondence: jiashenteh@usm.my; Tel.: +60-4-5996016
}

Received: 15 August 2018; Accepted: 10 September 2018; Published: 12 September 2018

\begin{abstract}
Power systems has been subjected to significant upgrades in terms of structure and capacity. Reliability evaluation of composite power systems has surfaced as an essential step in operation and planning stages of the modern power system. It is an effective tool to investigate the ability of power systems to supply customers with reliable power service. The purpose of this review is to enhance the knowledge of reliability studies conducted on composite power systems by providing a critical and systematic review. This work investigates peer-reviewed articles published between 2007 and 2017 in three reliable databases. The findings reveal that the reliability of composite power systems has received considerable attention over the last few years. Secondly, investigation studies demonstrated a crucial role in verifying the impact of adopting new technologies. Third, studies on this topic have been intensively conducted in Asia, which highlights the promising sectors in these regions. However, researchers have generally focused on developing several aspects (e.g., evaluation speed and wind power integration) at the expense of others (e.g., realistic studies and other renewable energy resources). The lack of practical applications is evident in the surveyed publications. These findings imply a potential incoordination between the needs of the real applications and researchers' tendencies. Future reliability evaluation scholars are advised to consider the findings of this systematic review including concentrating on insufficiently covered topics and enhance the coordination among the efforts devoted in this area.
\end{abstract}

Keywords: reliability analysis; composite power system; systematic literature review

\section{Introduction}

Rapid changes in modern life, especially in population, economy, and technology, have created a high demand for energy. Electricity is intertwined with most aspects of modern life because modern society considers it an indisputable right [1]. Maintaining a continuous power supply is an indicator of prosperity and national development. Therefore, providing customers with secure and reliable power is a priority of decision makers.

Fully reliable power systems do not exist due to many factors, such as random failures of system components, intermittent power sources, and uncertain load profile. System blackout may result from one or more of these factors in a conditional sense [2]. An inverse correlation exists between the investment cost of power systems and system reliability, as shown in Figure 1 [3]. This figure illustrates 
the correlation between the probability of interrupting power and the investment cost during planning and operation stages. Reliability can be improved by increasing the investment cost. User costs associated with failures decrease as reliability increases. The total life cycle cost is the summation of these two costs. The minimum point of the total life cycle cost is the optimum point of operation.

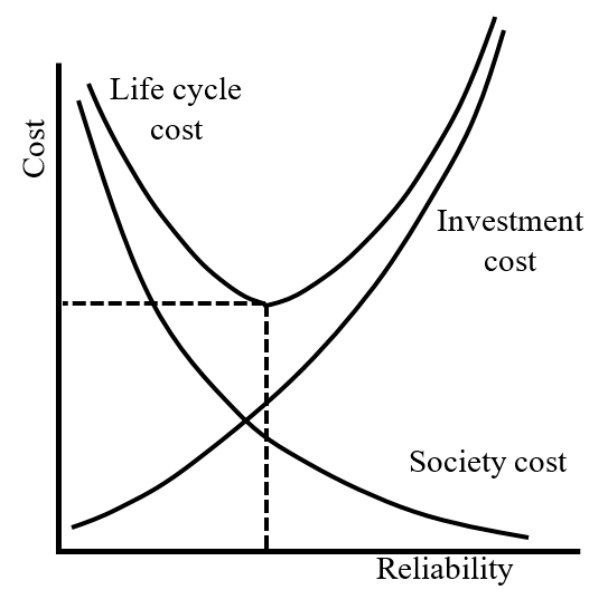

Figure 1. Correlation between reliability level and total system cost.

Therefore, a critical challenge in the planning and operation of power systems is to balance the trade-off between investment and reliability level [4]. The aim is to supply customers with acceptable power service while minimizing the purchasing cost [5]. These acceptable standards are determined by either regulation or customers' needs [6].

Power systems have undergone many upgrades and developments in the last few decades, not only in terms of system size but also in devices, components, structures, and power sources. This trend has made reliability evaluation a priority. Utility and independent system operators need to be comprehensively aware of the status of the system and its components. This information can be obtained by performing a reliability evaluation for the desired system [7].

Reliability evaluation of power systems, in which the quality of power systems is assessed, is an integral phase of the planning, design, and operation of all engineering systems [1,3]. This evaluation consists of two fundamental aspects, namely, security and adequacy assessment [8]. Security assessment determines the capability of the system to respond to sudden disturbances. Adequacy assessment indicates whether the system can satisfy the load demand at all times with the desired quality of service. [9]. Although reliability evaluation is basically concerned about the quality of electricity services, improving it is a key issue in enhancing the load supply [10].

Reliability evaluation consists of three major steps: system state selection, evaluating the selected state, and index calculation. In accordance with these stages, reliability evaluation can be solved by two basic approaches; (a) analytical techniques and (b) simulation-based techniques [11]. Analytical assessment is the fundamental method in reliability evaluation; however, simulation methods have been introduced to handle large systems and the random behavior of a system and its components [12].

The primary difference between the two methods is the process of state selection [13]. In analytical techniques, a system is represented by analytical models, and system risk is evaluated by indices from these models using mathematical solutions [14]. Reliability indices are estimated in analytical techniques on the basis of basic knowledge and mathematical models; the probabilities and frequencies of system conditions are recounted and combined [12]. These techniques are efficient in relatively small systems. Meanwhile, simulation techniques simulate a sequence of actual experiments on a system under random failure behavior of its components [15]. The indices are then assessed by observing the experiments. A hybrid methods were recently introduced to incorporate the advantages of the former techniques [16]. 
Simulation techniques are categorized into two methods, namely, sequential Monte Carlo simulation (MCS) and non-sequential MCS. In sequential MCS, the chronological characteristics of a system and component behavior are considered and simulated sequentially. This method accurately incorporates time-dependent variables, such as aging factor and sustainable energy resources, into the simulation [17]. Frequency and state duration indices can be calculated to obtain accurate and comprehensive results [7]. However, high computational burden and complexity are major obstacles in this category [18].

In non-sequential MCS, system states are obtained by randomly sampling the component state space without considering the chronology of the system and component behavior [19]. Despite its acceptable computational effort, it cannot be used in applications in which chronological behavior matters.

A power system is divided into three hierarchical levels from the point of view of reliability calculations. These levels are shown in Figure 2 [11]. In hierarchical level 1 (HL1), reliability is calculated based on generation characteristics only, in which transmission lines are assumed to be fully reliable. Both generation and transmission lines are considered in HL2. This level investigates the capability to provide an adequate and secure supply to customers by considering the transmission system constraints [20]. HL2 is sometimes called composite generation and transmission system or bulk power system. HL3 considers the analysis of an additional distribution facility [21]. This level is typically avoided because it is time consuming and complicated. This systematic literature review (SLR) examines articles relevant to HL2, in which the reliability of composite generation and transmission systems is studied.

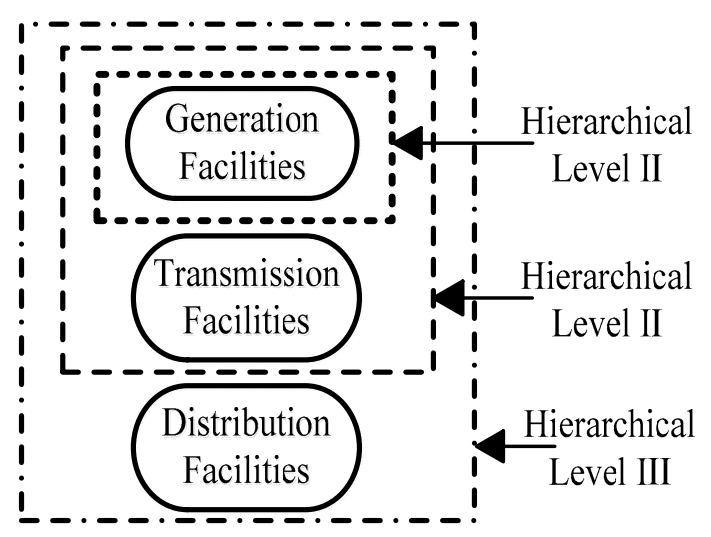

Figure 2. Hierarchical levels of power systems.

The literature has contributed to reliability studies on composite power systems by proposing new models [22,23], improving computation efficiency [19,24-26], improving accuracy [4,27,28], optimization [15,29-31], and differentiation of alternatives [32,33]. The reliability of composite generation and transmission systems plays a crucial role in system evaluation. It provides planners and decision makers with valuable and intuitively interpretable information [34]. However, a review that systematically gathers such work in this area is still needed.

Climate change and depletion of fossil fuel resources has become a global concern since few decades. Renewable energy resources have been considered the promising alternative of the conventional power sources [35]. Although integrating renewable resources into a grid is seen as a viable option, it may distort the ordinary power grid due to the intermittent behavior of this resources [36].

Most of renewable energy resources are characterized by high variability and uncertainty which pose major challenges system reliability [37]. High penetration of intermittent power generation will bring negative impact to power distribution network. Improper penetration of the intermittent power source may into the grid may result in significant reverse power flow which leads to unacceptable 
voltage rise on distribution feeder [38]. Overvoltage may trigger the protection in the system causing voltage fluctuation and sudden change in power flow. Recurrence of this phenomenon does not only disturb power supply, but also shortens the lifetime of system components. Thus, the system is exposed to a high risk for increased maintenance costs and power outages [39]. Some solutions were proposed to mitigate the adverse effects of high intermittent power penetration through STATCOM device [40], inverter control techniques [41], and energy storage system [42].

Weather conditions have a significant impact on renewable power generation and transmission systems, and in turn, on the reliability indices [43]. Penetration of renewable power resources and independent system operators demonstrated high Power system restructuring. The conventional techniques of reliability evaluation are no longer applicable for accurately assessing this level of uncertainty and complexity [44]. Systems operators and planners require new computational tools capable of handling these characteristics, in addition to the recent power system market specifications [45].

Smart grid is a modern infrastructure of power grid. It was introduced as a measure to improve efficiency, reliability, and safety of the restructured power system. It is also capable to mitigate the negative effects of integrating renewable energy sources, through modern communication and control technologies [46]. Supply side management and demand-side management (DSM) are two strategies that enables the implementation of smart grid. Some of DSM programs demonstrated considerable improvement in reliability of power systems; preventive load shifting, corrective load shifting [47], load shifting [48], and Peak-clipping [49].

Dynamic Thermal Rating (DTR) is another smart grid technology for improving the reliability of the overall network. It allows the conductor to operate at higher capacity based on its ambient factors and the line condition [50]. A conductor works under DTR can mostly transmit current $20 \%$ higher than its static rating [51]. This technology is highly recommended to be implemented in case of penetrating intermittent power source into the grid (e.g., wind power). Although it does not necessarily provide the best reliability, it could lead to avoiding costly reinforcement of transmission network [52].

Microgrids (MGs) are a relatively new concept developed in order to improve the system reliability [53]. The term refers to a group of radial feeders composed of a mix of loads, small generation systems, and local storage [54]. MGs may operate in two modes: grid-connected and islanded. In a grid-connected mode, the MG is connected to the utility grid, importing or exporting energy. The islanded mode is enabled when a failure occurs in the upstream grid. Each feeder must have at least a source rated to satisfy the sensitive load in islanded mode [53].

Renewable energy sources are essential components of MGs, they are relied upon to fulfil the load demand in islanded mode [55]. MG's ability to increase renewable energy penetration has become attractive and important research topic [56]. A MG controller is required to ensure proper operation while working in its two modes [57]. A MG is normally subjected to a wide range of analysis applications (e.g., unsymmetrical faults, short circuit analysis and reactive power planning) to verifying its reliability and efficiency [58]. Short circuit faults in power systems can be broadly classified into two categories; symmetrical and unsymmetrical faults [59]. Symmetrical faults occur in two forms; 3-pahse short circuit involving the ground, or without the ground. Unsymmetrical faults occur between line and ground, line and line, or double line and ground [60].

$\mathrm{N}-1$ contingency analysis is used in the planning phase and reliability studies on power systems to ensure that any single credible contingency will not exacerbate into cascading failures [61]. Power systems are normally planned to cover the load demand in normal condition and N-1 contingency condition [62]. N-2 contingency simulation is used to analyze the loss of two elements simultaneously, while the loss of two elements consecutively is analyzed via N-1-1 contingency simulation [63].

In this review, we seek to provide researchers and decision makers with a comprehensive view of the latest contributions of reliability studies on composite power systems. The objective of this SLR is to discuss the literature between 2008 and 2017. The work conducted in the past 10 years is 
summarized, and gaps are professionally identified for further research and development. This SLR maps the research landscape from the literature onto a coherent taxonomy, and discovers the key features that characterize this emerging line of research.

The organization of this SLR is as follows: the methodology for selecting the target literature and inclusion criteria is described in Section 2. Taxonomy of the literature and brief descriptions of the categories are presented in Section 3. The target literature has been discussed in Section 4 in terms of category, motivation, challenges, and recommendations. Finally, the conclusions are summarized in Section 5.

\section{Method}

The most important keyword in the topic covered by this SLR is "reliability." However, the reliability concept is adopted in many engineering topics. Therefore, articles on reliability in areas other than power systems were excluded in this review. We limited our scope to the reliability of composite power systems apart from HL1 and HL3 for specialization. This section is divided into several subheadings. The experimental results are described and interpreted concisely, and experimental conclusions are established.

\subsection{Information Sources}

A comprehensive survey was conducted to locate all articles relevant to the reliability of composite power systems by searching highly reliable databases, namely, the IEEE Xplore library of highest-quality technical literature in engineering and technology; Science Direct, which is a trustworthy source of scientific, technical, and medical research; and the Web of Science (WoS) platform, which indexes cross-disciplinary articles in science, social science, arts, and humanities [64]. The combination of these sources covers high-ranked studies on reliability concepts in composite power systems and provides a broad view of dedicated efforts.

\subsection{Study Selection}

Selection of the target studies was initialized by searching the abovementioned databases, followed by two iterations, namely, screening and filtering. The first iteration involved excluding duplicates and irrelevant articles after scanning their titles and abstract. In the second iteration, the articles filtered from the first step were analyzed and classified through full-text reading. Eligibility criteria were followed in the selection process.

\subsection{Search}

The search was implemented in one year, starting from March 2017. We began by reading review papers to identify an appropriate query. The derived query was then inserted in the advanced search box of IEEE Xplore, Science Direct, and WoS. The query contained a mix of the keywords "reliability evaluation" and "composite power systems" in different peers and variations, as shown in the top of Figure 3. Conference proceedings, working papers, books, and other types of reports were excluded to ensure the quality of the findings. Non-English literature was also disregarded. This SLR mainly relied on journal articles because they are the foremost source of up-to-date contributions and proper scientific work relevant to our SLR aims.

To concentrate on the latest studies, this SLR focused on articles published in the past 10 years (between 2008 and 2017). The field of interest is HL2; thus, the other layers were excluded from the study. The initial target of this SLR is to map the space of articles into a general and coherent taxonomy with four main categories. After removing the duplicates, we excluded several articles in both iterations on the basis of the eligibility criteria shown in Figure 3. The exclusion justifications were as follows: (1) non-English articles because understanding their content is difficult; (2) reliability studies applied to systems other than power systems; (3) the focus is on HL1 or HL3; (4) the main 
contribution of the article is not in the interest of the reliability of composite power systems; and (5) the article studies only the transmission line considering fully reliable generation.

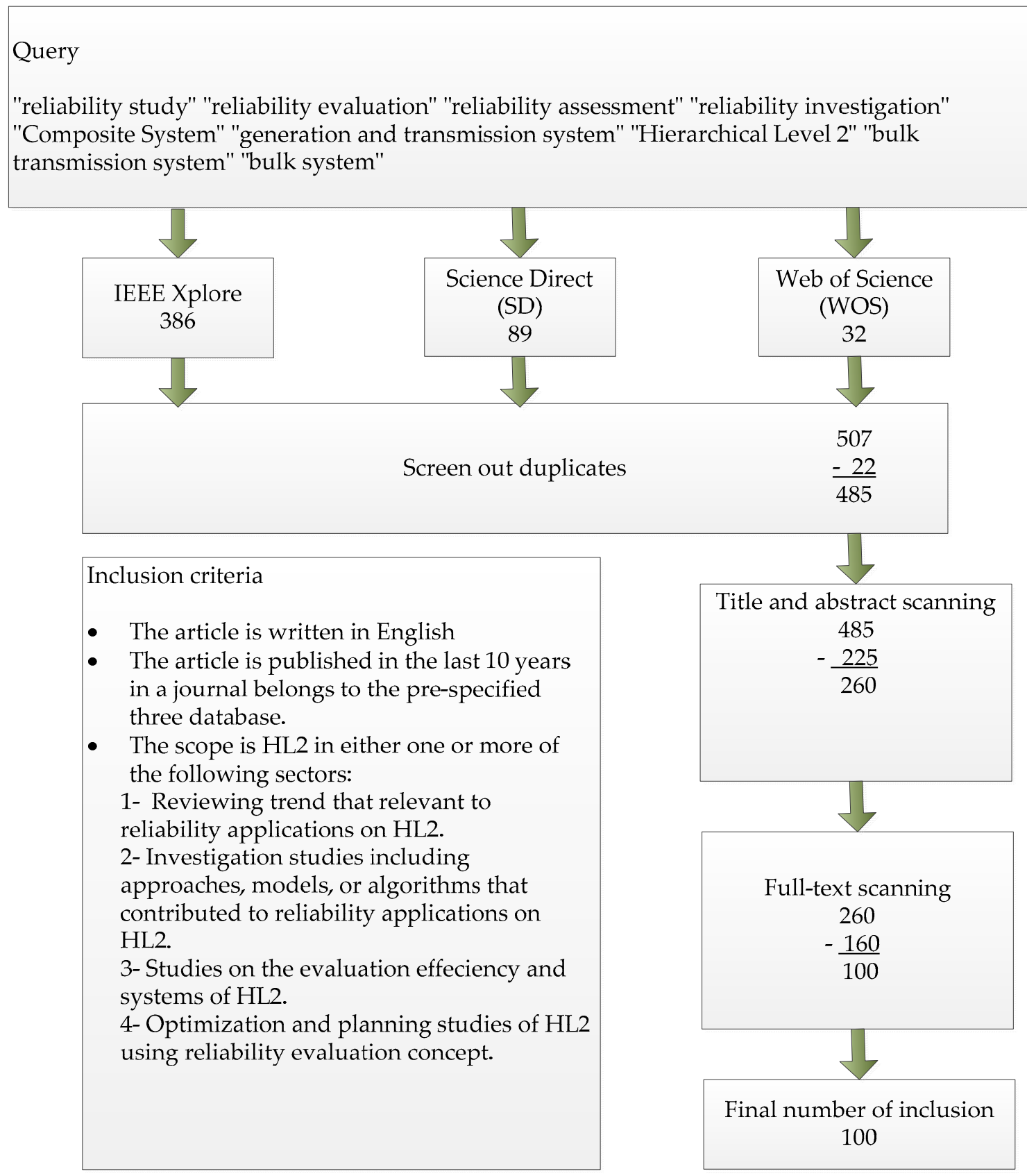

Figure 3. Flowchart of study selection, including the search query and inclusion criteria.

\subsection{Data Collection}

The papers obtained from the three databases were imported to Mendeley. The first iteration was then launched using available Mendeley tools. The data of these papers were placed in a single Excel file to facilitate access to the contents and analyze them, and a space was allotted in the file to highlight the most valuable contents. Full-text readings were performed on the articles inferred from the second filtration. All comments and notes were initially saved on the pdf versions of the articles, followed by summarization and tabulation of the most significant findings and outlines using the Excel file. 


\section{Results}

The query in Figure 3 was searched using the three databases. The search resulted in 485 articles published from 2008-2017. Three hundred eighty-six articles were obtained from IEEE Xplore, 89 articles from ScienceDirect, and 32 articles from WoS. Twenty-two articles were deducted in the first filtration step due to duplication in the three databases. Two hundred sixty articles remained after scanning the titles and abstracts. The full-text scanning phase eliminated 160 articles, leaving 100 in the final included set. This set was read thoroughly to derive an inclusive taxonomy of the searches conducted on the reliability of composite power systems.

Investigation studies accounted for the largest portion, represented 35 out of $100(35 \%)$ articles. They examined the effects of some factors on composite power system reliability. Most of them included the proposal of a new model of system components and studied the impacts of these components on power system reliability. Planning and optimization studies is the second largest portion and represented 34 out of $100(34 \%)$ articles. They focused on power system reliability in the planning phase. Studies that concentrated on the evaluation process accounted for $29(29 \%)$ articles, and most of them handled the simulation computational efficiency issue. The smallest portion of the articles, two $(2 \%)$, reviewed literature on the reliability of composite power systems. This pattern was critically observed and then mapped to general categories. The main categories were distinguished into several subcategories to highlight the main contributions of the gathered studies. We refined the classification into the taxonomy shown in Figure 4. In the following sections, we list the categories with elaboration. Simple statistics are provided throughout the discussion.

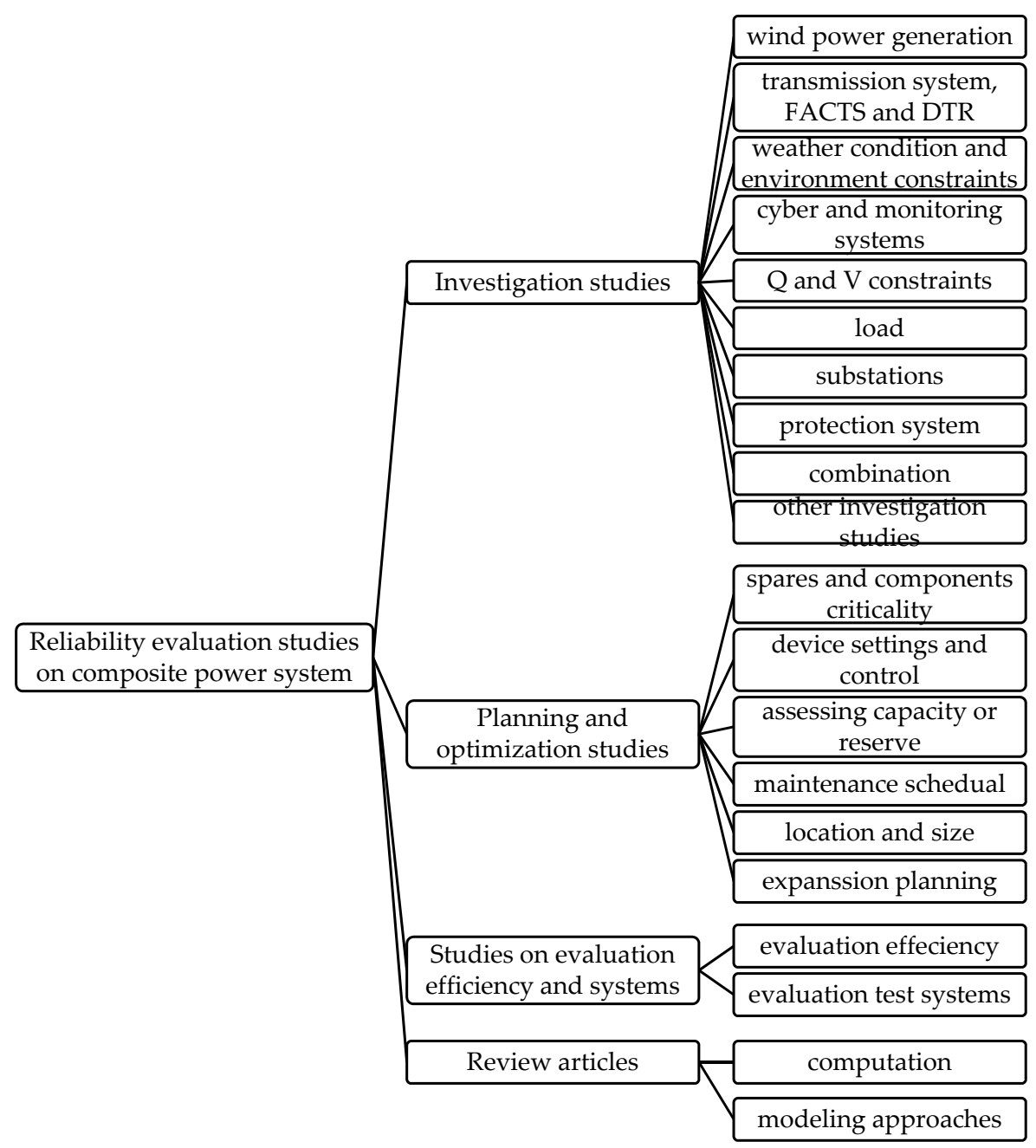

Figure 4. Taxonomy of reliability studies on composite power systems. 


\subsection{Investigation Studies}

Given that the main objective of reliability evaluation is to investigate system reliability [65], the largest group mainly comprised investigation studies. They can be divided into two main trends, namely, investigating the effect of integrating a technology into a power system and investigating the impact of considering a new parameter in the reliability evaluation process.

Power system structure has been improving to satisfy the global demand and keep pace with the technology revolution. The interdependency of electricity system and other energy resources is prominently obvious. Studies that investigated the effect of integrating wind power into composite power system reliability were highlighted in the first subcategory. Several attempts [66-69] were conducted to acquire a realistic wind power generation model. Another study [70] aimed to quantify the influence of generation and/or transmission equipment on wind power curtailment events.

Another subcategory focuses on reliability studies conducted on transmission lines, including Flexible AC Transmission Systems (FACTS) and DTR systems. A methodology to model a high-voltage direct current transmission system tapped by a voltage-sourced converter was proposed in [71]. Reference [72] investigated the effects of line-switching operations on HL2 reliability. References $[73,74]$ investigated incorporating FACTS devices into HL2 reliability evaluation. The impact of DTR was studied in $[20,75]$.

The increasing dependency of power utilities on cyber and monitoring systems has revealed the necessity of considering them in reliability studies of composite power systems. Effect of cyber-attack scenarios on wind power integrated system were discussed in [76]. The difficulties of considering cyber-induced dependent failures in reliability studies on composite power systems were discussed and a solution was proposed in [77]. A methodology was proposed in [78] to investigate the effect of cyber-malfunctions in substations on composite power system reliability. Effect of malfunctions of a Wide-Area Measurement System (WAMS) on composite power system reliability was studied in [79].

The environment affects the reliability of HL2, as concluded by the authors in $[80,81]$, who considered hurricane impact and emission constraints in reliability evaluation, respectively. Effect of $Q$ and V constraints [28], load uncertainty [82], and substations [10], were investigated in composite system reliability evaluation. Various studies on protection systems were conducted. A new technique was proposed in [22] to model protection system failures in order to include them in the reliability evaluation process. IEC 61850-based substation protection systems were modeled in [83]. A Bayesian network-based analytical methodology was proposed in [84] to investigate the impacts of protection system failures on HL2 system reliability.

Most of the studies in the next subcategory investigated a combination of the subcategories mentioned previously. Transformers, lines, generators, and loads were modeled in [85]. Wind power is a common factor in the remaining articles of this subcategory. References $[86,87]$ investigated the effect of combining wind power and DSM on HL2 reliability. The effect of penetrating wind power together with hydropower on HL2 reliability was investigated in $[88,89]$. The load point reliability in HL2 considering wind power integration was discussed in [90]. Only one study [91] investigated the combination of wind power and solar power generation, and another [92] focused on the combination of wind power and energy storage system. The reliability of an electrical network that incorporates DTR and wind farm was investigated in [93].

Several investigations were included in the last subcategory. A comparison of load models was conducted in [4]. Actual results of contingency enumeration and MCS techniques were compared in [94]. The importance of considering probability distribution functions in reliability analyses was verified in [95]. Reference [96] investigated the impact of transient instability on power system reliability.

\subsection{Planning and Optimization Studies}

The second largest category of articles (34/100) comprised planning and optimization studies that attempted to apply the reliability concept in planning phases or optimizing a certain system. 
Reliability evaluation plays a crucial role in planning and operation phases [15]; hence, it overlaps with most of power system planning processes, as shown in the subcategory list.

A method to assess the number of spare breakers required in high-voltage transmission stations was proposed in [97]. A new methodology was proposed in [9] to evaluate the criticality of substations in a power system on the basis of the static and dynamic performance of their equipment outages. Methods for identifying critical nodes and components in power networks were presented in [98,99], respectively. The authors in [100] proposed an approach to determine the reliability importance of power plants or energy producers from the perspective of consumers or distribution companies.

The control mode and settings of a Unified Power Flow Controller (UPFC) were optimized in [101] to improve the reliability of composite power systems. A methodology was proposed in [15] to determine the optimal reliability indices of system components included in a composite electric power system. Optimal implementation of a network-driven load management program was addressed in [102] to enhance the composite system reliability.

A procedure to schedule spinning reserve capacity on the basis of the desired level of reliability was proposed in [103]. In [104], the authors considered the failures and capacity constraints of transmission systems in assessing the spinning reserve. Others in [29] proposed a day-ahead allocation method of operation reserve that considers wind power prediction and transmission system constraints. A methodology for assessing the power capacity availability at load buses was presented in [1]. Wind capacity credit was examined in [105] in consideration of generating unit outage parameters and hourly load demands. Reference [106] described a methodology to determine transmission network adequacy in systems with conventional and wind power units. A similar study was conducted in [107] on the basis of the concept of chronological power flow.

Maintenance planning in composite power systems has been studied from various aspects. A methodology to schedule preventive maintenance was described in $[108,109]$ by optimizing the three objectives of maintenance, reliability, and failure costs. A maintenance planning approach was proposed in [110] to determine the optimal time-based maintenance for circuit breakers. Another approach was provided in [111] for identifying the critical components in HL2 to obtain focused maintenance management. The authors in [112] obtained a cost-effective replacement framework that considers the overall system reliability and component criticality.

Six of the articles developed approaches for optimizing the locations or sizes of certain components in HL2. In [30,32] the authors focused on setting energy storage systems in the presence of wind power generation. A method for the allocation of available transfer capability was proposed in [113]. An approach was proposed in [26] to find the optimal location of distributed static series compensators. The authors in [114] aimed to determine the adequate size of on-site energy storage and the transmission upgrades that are needed in connecting wind power sources to systems. The optimal location, size, and year of installing energy resources were discussed in [115], and a reliability analysis-based framework was proposed.

The literature on expansion planning includes active attempts to handle wind power generation. The authors of [116] exploited transmission expansion planning to maximize the penetration of wind power into grids. Expansion planning approaches were proposed in [117-119] in consideration of wind power generation. Another approach for dynamic expansion planning was presented in [120]. Reliability-based planning of Demand Response (DR) programs was addressed in [121]. A multi-objective optimization technique for HL2 expansion planning was presented in [122] in consideration of cost and reliability assessment.

\subsection{Studies on Evaluation Efficiency and Systems}

Considerable effort has been exerted to improve the efficiency of the reliability evaluation process. Accuracy and computational cost in reliability evaluation are usually in conflict. Articles in the evaluation efficiency subcategory can be divided into three trends according to their objectives, as shown in Table 1. 
Table 1. Categorization of articles in the evaluation efficiency subcategory according to the main purpose.

\begin{tabular}{ccc}
\hline Computational Burden & Accuracy & Computational Burden and Accuracy \\
\hline Mori 2011 [8] & Bordeerath 2012 [127] & Shu 2014 [17] \\
Amaral 2010 [19] & - & Pindoriya 2011 [25] \\
Sun 2010 [24] & - & Mosadeghy 2016 [27] \\
Wang 2014 [65] & - & He 2010 [33] \\
Green 2013 [125] & - & Safdarian 2014 [132] \\
Benidris 2015 [126] & - & Liu 2017 [134] \\
Yongji 1999 [130] & - & Hou 2017 [136] \\
Chen 2013 [135] & - & - \\
Akhavein 2011 [137] & - & - \\
Tómasson 2017 [131] & - & - \\
Hua 2013 [138] & - & - \\
Kim 2013 [139] & - & - \\
Hua 2015 [140] & - & - \\
Silva 2008 [123] & - & - \\
Hong 2009 [124] & - & - \\
Liu 2010 [129] & - & - \\
Hou 2016 [5] & - & - \\
Kumar 2017 [128] & - & \\
\hline
\end{tabular}

Methods for well-being analysis were presented in $[19,123]$ on the basis of non-sequential MCS. Other approaches that incorporate a deterministic approach with a probabilistic approach were proposed in [33,124]. State space classification techniques were proposed in [125,126]. A least-squares support vector machine classifier was combined with MCS in [25] to achieve an accurate and computation-efficient simulation. Reference [127] sought to improve classifier precision. An algorithm was proposed in [128] for reliability analysis on the basis of a modified minimal cut set approach. In Reference [129], a Markov cut-set-based reliability evaluation was proposed to accelerate the simulation in the case of numerous system operational considerations. A continuous-time Markov chain-based sequential reliability assessment was discussed in [5]. References $[7,130,131]$ developed an evaluation technique based on cross-entropy methods. A novel adaptive importance sampling technique was obtained in [65] to improve the efficiency of short-term reliability evaluation.

An importance sampling technique was combined with antithetic variates in [135] to handle cascading failures. The equivalent network concept was applied in [137] to overcome the obstacles of the reliability evaluation of a large-scale HL2 system. A new method for probabilistic evaluation was proposed in [8] on the basis of a multi-objective meta-heuristic method. The evaluation process was accelerated in [138] by eliminating redundant line flow constraints. A splitting method was examined in [139] to efficiently evaluate large blackout probabilities. MCS was improved in $[17,24,134]$ on the basis of the dagger sampling technique, accelerated state evaluation approach, and estimation of distribution algorithm, respectively. The authors in [136] improved the quasi Monte Carlo method on the basis of the dimension importance sorting method to accelerate the simulation with high accuracy. AC power flow formulation was approximated in [132] to be able to consider active and reactive power in the reliability evaluation of HL2. The computational burden was reduced in [140] by extracting significant system states. Additional capabilities were added to HL2 reliability evaluation after applying Bayesian networks in [133]. A fast and accurate time-dependent approach was proposed in [27] to efficiently model time dependency and correlations in HL2 integrating renewable energy resources.

The second subcategory in this category includes only one study that improved a test system for HL2 reliability evaluation. The test system presented here [141] is a real high-voltage network in a province of south Iran. This system contains information necessary for research purposes. 


\subsection{Review Articles}

The final and smallest set of articles in this taxonomy is review articles that focused on reliability evaluation of HL2. Only one article [142] discussed the reduction technique directly or indirectly related to the adequacy equivalents of HL2. Another article [143] in this category focused on the important factors and considerations required to conduct an adequacy assessment of a wind-integrated HL2 system.

\section{Discussion}

This SLR aims to obtain a comprehensive view of studies conducted on HL2 reliability. It focuses on recent work related to HL2 reliability conducted between 2008 and 2017. This field lacks review articles, which posed an obstacle to the researcher. The trends of studies on this topic were highlighted here to develop a taxonomy.

A taxonomy built based on recent literature on a research topic can provide various benefits. In view of HL2 reliability, many studies have been implemented. Much time and effort are required to evaluate these studies without a thorough classification. Providing a taxonomy of the published articles would organize this set of publications. A new researcher interested in HL2 reliability could feel overwhelmed by the massive number of articles that handle this topic when no organizational structure is available. Therefore, the researcher could fail to determine the right trend. Various academic studies have addressed this topic from the investigation perspective. Others have introduced planning methodologies, and several have improved the evaluation process. Developing a taxonomy of the related publications can help sort these studies into a coherent layout.

A taxonomy with an organized structure provides a researcher with functional insights into the target field. First, the taxonomy helps the researcher highlight a potential trend of research on a specified topic. Second, the taxonomy assists the researcher in identifying gaps among the published work. Classifying HL2 reliability studies into distinct categories would reveal the weaknesses and strengths of this research area.

This SLR showed how researchers were interested in investigation studies to evaluate the effects of factors on HL2 reliability. Planning studies have also attracted the attention of numerous researchers. Review articles, by contrast, have not received adequate attention. The literature does not cover various types of renewable energy resources. Wind power has received considerable attention from researchers compared with other power resources. Studies on proposing an efficient and realistic test system have not been paid sufficient attention. A further discussion of the findings is presented in the remaining portion of this SLR.

A comprehensive insight into the target literature is provided in Table 2. These are the articles which satisfy the inclusion criteria shown in Figure 3. In this table, categories and contributions of the articles are compared. 
Table 2. Comparison of the notable studies conducted on composite power system reliability (2008-2017).

\begin{tabular}{|c|c|c|c|c|}
\hline & Source & & Category & Contribution \\
\hline $\begin{array}{l}\text { Effects of Wind Power on Bulk System Adequacy } \\
\text { Evaluation Using the Well-Being Analysis Framework. }\end{array}$ & [69] & \multirow{11}{*}{$\begin{array}{l}\text { Investigation } \\
\text { studies }\end{array}$} & \multirow{5}{*}{ wind power generation } & $\begin{array}{l}\text { Obtained a framework to study the impacts of wind power, } \\
\text { load forecast uncertainty and their interactive effects on system } \\
\text { reliability in HLII using the Well-Being Analysis }\end{array}$ \\
\hline $\begin{array}{l}\text { Integration of large-scale wind farm projects including } \\
\text { system reliability analysis. }\end{array}$ & [68] & & & $\begin{array}{l}\text { developed a comprehensive procedure to investigate the impact } \\
\text { of a wind farm project considering transmission system losses } \\
\text { cost, load delivery point interruption cost and operating cost of } \\
\text { conventional generating units }\end{array}$ \\
\hline $\begin{array}{l}\text { Probabilistic Wind Energy Modeling in Electric } \\
\text { Generation System Reliability Assessment. }\end{array}$ & [67] & & & $\begin{array}{l}\text { Proposed several models of wind resources integration and } \\
\text { presented approach to investigating the impact of these models } \\
\text { on composite power system reliability. }\end{array}$ \\
\hline $\begin{array}{l}\text { Probabilistic Analysis for Maximizing the Grid } \\
\text { Integration of Wind Power Generation. }\end{array}$ & [70] & & & $\begin{array}{l}\text { Presented a Sequential MCS algorithm to evaluate the reliability } \\
\text { indices of a wind power integrated system, in addition to } \\
\text { characterize wind power curtailment events. }\end{array}$ \\
\hline $\begin{array}{l}\text { A novel method for reliability and risk evaluation of } \\
\text { wind energy conversion systems considering wind } \\
\text { speed correlation. }\end{array}$ & [66] & & & $\begin{array}{l}\text { Proposed a new methodology based on Weibull-Markov } \\
\text { method to evaluate reliability of bulk power systems } \\
\text { incorporating large-scale wind generation system, considering } \\
\text { DFIG wind turbines, wind speed correlation and wind turbine } \\
\text { outage. }\end{array}$ \\
\hline $\begin{array}{l}\text { Composite System Reliability Assessment } \\
\text { Incorporating an Interline Power-Flow Controller. }\end{array}$ & [73] & & \multirow{6}{*}{$\begin{array}{l}\text { Transmission system, } \\
\text { FACTS, DTR }\end{array}$} & $\begin{array}{l}\text { Proposed an approach to investigate the impact of an Interline } \\
\text { Power-Flow Controller(IPFC) on composite power system. }\end{array}$ \\
\hline $\begin{array}{l}\text { Reliability Evaluation of an HVDC Transmission } \\
\text { System Tapped by a VSC Station. }\end{array}$ & [71] & & & $\begin{array}{l}\text { Presented evaluation a methodology to investigate the } \\
\text { reliability of an HVDC transmission system with a VSC tapping } \\
\text { station. }\end{array}$ \\
\hline $\begin{array}{l}\text { Probabilistic Worth Assessment of Distributed Static } \\
\text { Series Compensators. }\end{array}$ & [74] & & & $\begin{array}{l}\text { Developed a reliability model for Distributed Static Series } \\
\text { Compensators and investigates their impacts on composite } \\
\text { power system reliability. }\end{array}$ \\
\hline Reliability Modeling of Dynamic Thermal Rating. & [75] & & & $\begin{array}{l}\text { Proposed an approach based on Markov model for reliability } \\
\text { studies on power lines equipped with DTR system. }\end{array}$ \\
\hline $\begin{array}{l}\text { Studying the Reliability Implications of Line } \\
\text { Switching Operations. }\end{array}$ & [72] & & & $\begin{array}{l}\text { Proposed a method to investigate the implications of line } \\
\text { switching operations on composite power system reliability. }\end{array}$ \\
\hline $\begin{array}{l}\text { Impact of the Real-Time Thermal Loading on the Bulk } \\
\text { Electric System Reliability. }\end{array}$ & [20] & & & $\begin{array}{l}\text { Proposed a methodology to investigate the impact of high } \\
\text { loading of power lines equipped with DTR system on } \\
\text { composite power system reliability. }\end{array}$ \\
\hline
\end{tabular}


Table 2. Cont

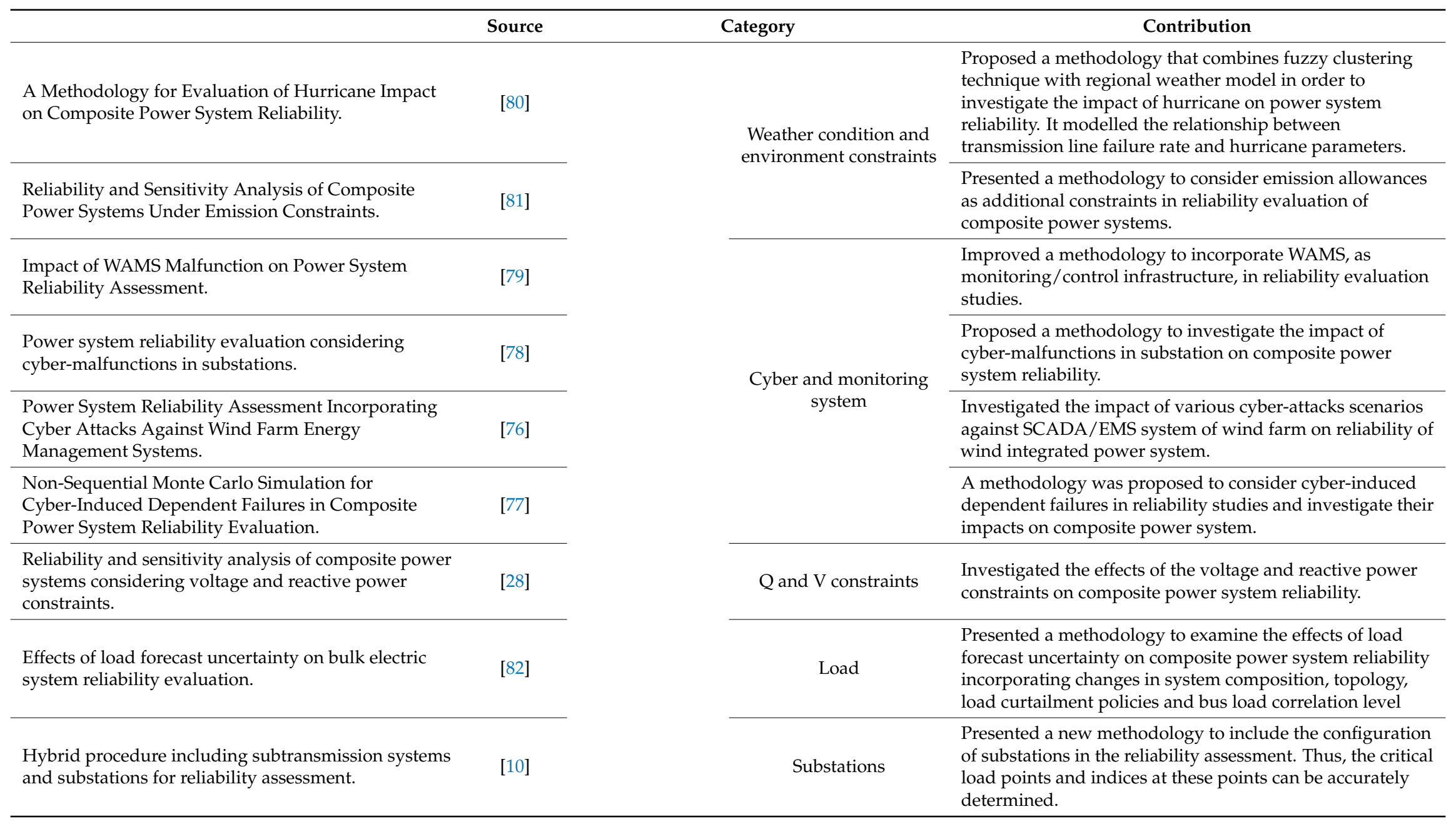


Table 2. Cont.

\begin{tabular}{|c|c|c|c|}
\hline & Source & Category & Contribution \\
\hline $\begin{array}{l}\text { Reliability Modeling and Analysis of IEC } 61850 \text { Based } \\
\text { Substation Protection Systems. }\end{array}$ & [83] & \multirow{3}{*}{ Protection System } & $\begin{array}{l}\text { Developed a methodology for modeling and analysis of IEC } \\
61850 \text { based substation protection systems. }\end{array}$ \\
\hline $\begin{array}{l}\text { New Models and Concepts for Power System } \\
\text { Reliability Evaluation Including Protection System } \\
\text { Failures. }\end{array}$ & [22] & & $\begin{array}{l}\text { Developed a technique to incorporate the effect of multiple } \\
\text { component outages resulting from the protection failures } \\
\text { into power system reliability evaluation. }\end{array}$ \\
\hline $\begin{array}{l}\text { Incorporation of protection system failures into bulk } \\
\text { power system reliability assessment by Bayesian } \\
\text { networks. }\end{array}$ & [84] & & $\begin{array}{l}\text { Proposed a Bayesian network based methodology for } \\
\text { modelling and investigating the impact of protection } \\
\text { system failures on bulk power system reliability. }\end{array}$ \\
\hline $\begin{array}{l}\text { Power System Risk Assessment Using a Hybrid } \\
\text { Method of Fuzzy Set and Monte Carlo Simulation. }\end{array}$ & [85] & \multirow{8}{*}{ Combination } & $\begin{array}{l}\text { Proposed a hybrid method of fuzzy set and Monte Carlo } \\
\text { simulation for modeling system component outage } \\
\text { parameters and load curves. }\end{array}$ \\
\hline $\begin{array}{l}\text { DSM Considered Probabilistic Reliability Evaluation } \\
\text { and an Information System for Power Systems } \\
\text { Including Wind Turbine Generators. }\end{array}$ & [87] & & $\begin{array}{l}\text { Developed a methodology for reliability evaluation of wind } \\
\text { integrated power system considering DSM and A web } \\
\text { based online daily time interval reliability integrated } \\
\text { information system (WORRIS). }\end{array}$ \\
\hline $\begin{array}{l}\text { Incorporating multiple correlations among wind } \\
\text { speeds, photovoltaic powers and bus loads in } \\
\text { composite system reliability evaluation. }\end{array}$ & [91] & & $\begin{array}{l}\text { Proposed a methodology for reliability evaluation of } \\
\text { wind-PV power integrated system incorporating multiple } \\
\text { correlations among solar radiation, wind speeds, and the } \\
\text { bus/regional loads. }\end{array}$ \\
\hline $\begin{array}{l}\text { Power System Reliability Impact of Energy Storage } \\
\text { Integration With Intelligent Operation Strategy. }\end{array}$ & [92] & & $\begin{array}{l}\text { Investigated the impacts of installing energy storage system } \\
\text { in wind power integrated system. }\end{array}$ \\
\hline $\begin{array}{l}\text { Impact of the Combined Integration of Wind } \\
\text { Generation and Small Hydropower Plants on the } \\
\text { System Reliability. }\end{array}$ & [88] & & $\begin{array}{l}\text { Assessed the impacts of integrating wind power system } \\
\text { together with small hydropower plants on the reliability of } \\
\text { composite power system. }\end{array}$ \\
\hline $\begin{array}{l}\text { Short-Term Impacts of DR Programs on Reliability of } \\
\text { Wind Integrated Power Systems Considering } \\
\text { Demand-Side Uncertainties. }\end{array}$ & [86] & & $\begin{array}{l}\text { Investigated the impact of DSM programs on short-term } \\
\text { reliability of wind-integrated power systems. }\end{array}$ \\
\hline $\begin{array}{l}\text { Reliability Impact of Dynamic Thermal Rating System } \\
\text { in Wind Power Integrated Network. }\end{array}$ & [93] & & $\begin{array}{l}\text { Proposed a methodology to investigate the impact of } \\
\text { adopting DTR system in a wind integrated power system. }\end{array}$ \\
\hline $\begin{array}{l}\text { A Model to Represent Correlated Time Series in } \\
\text { Reliability Evaluation by Non-Sequential Monte Carlo } \\
\text { Simulation. }\end{array}$ & [89] & & $\begin{array}{l}\text { Proposed a new stochastic model to investigate the impacts } \\
\text { of time-varying elements such as loads, wind power } \\
\text { generation, and water inflows on composite power system } \\
\text { reliability. }\end{array}$ \\
\hline
\end{tabular}


Table 2. Cont.

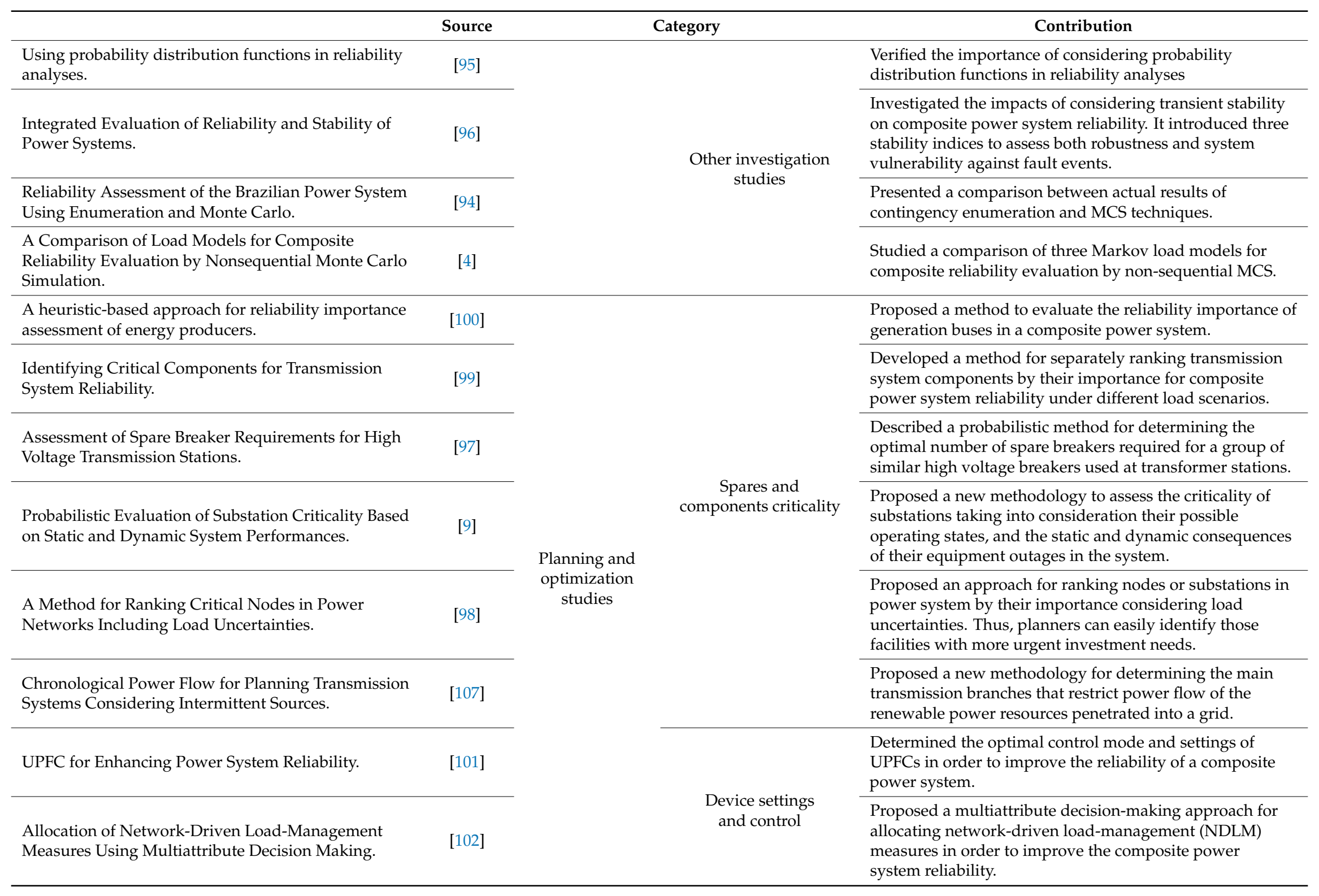


Table 2. Cont

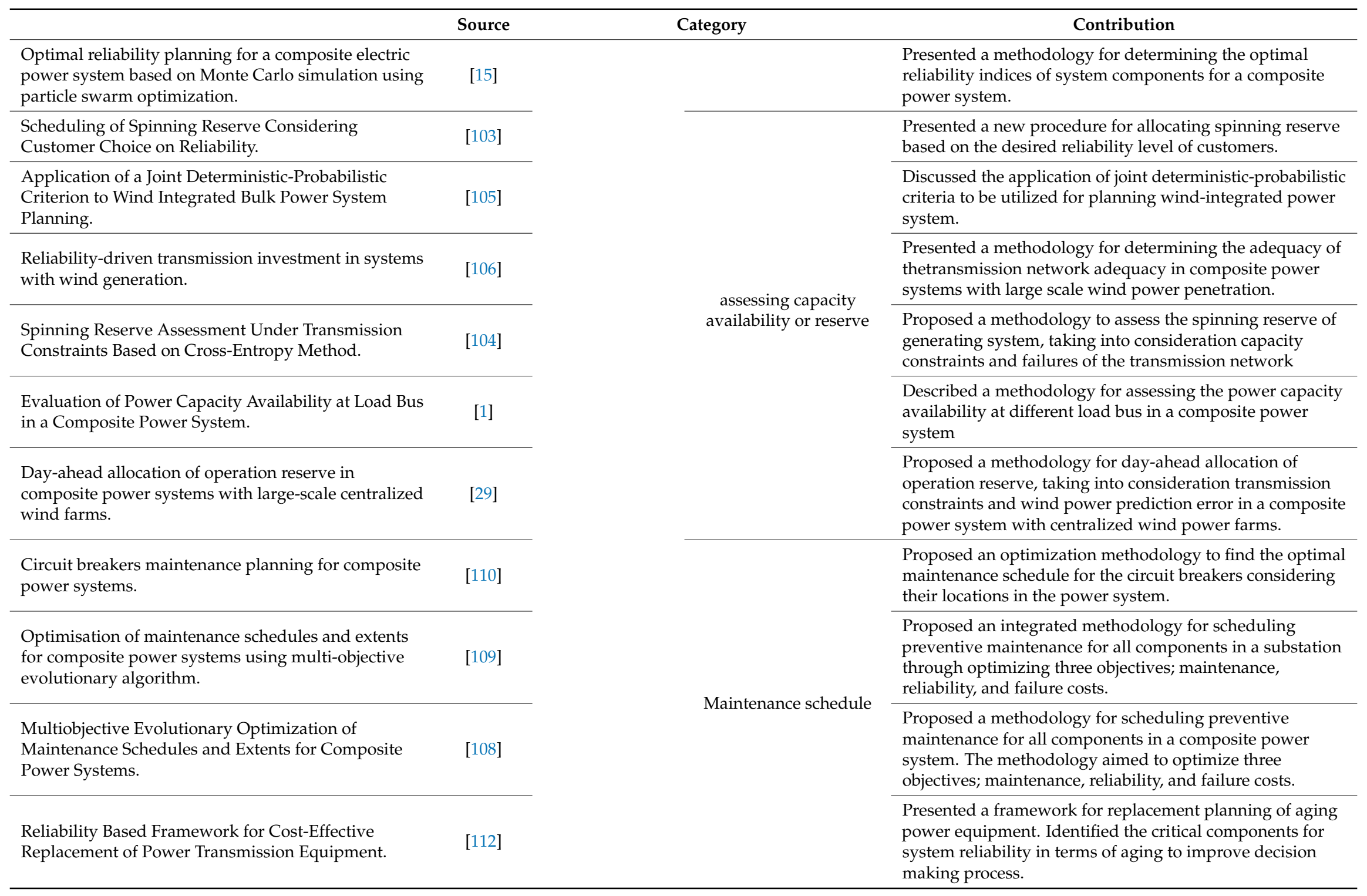


Table 2. Cont.

\begin{tabular}{lc}
\hline & Source \\
\hline $\begin{array}{l}\text { Identifying critical components for reliability centred } \\
\text { maintenance management of deregulated power } \\
\text { systems. }\end{array}$ & {$[111]$} \\
\hline $\begin{array}{l}\text { Optimal Allocation of Available Transfer Capability in } \\
\text { Operating Horizon. }\end{array}$ & {$[113]$} \\
\hline & \\
Energy Storage Application for Performance & \\
Enhancement of Wind Integration. & [26] \\
\hline $\begin{array}{l}\text { Optimal distributed static series compensator } \\
\text { placement for enhancing power system loadability } \\
\text { and reliability. }\end{array}$ & \\
\hline $\begin{array}{l}\text { Clustering Technique Applied to Nodal Reliability } \\
\text { Indices for Optimal Planning of Energy Resources. }\end{array}$ & [115] \\
\hline
\end{tabular}

\section{Category} Contribution

Proposed a computationally efficient approach for

identifying the criticality of system components considering

the additional long-term system costs imposed when they

fail.

Proposed an approach for identifying the optimal allocation of Available Transfer Capability

Developed a generic algorithm-based approach for optimizing sizes, places and schedules of storage systems installed into a wind integrated power system. Thus, reliability of the system can be enhanced using optimal setting of the energy storage system.

Proposed an approach for optimizing the locations of distributed static series compensators in order to enhance the system reliability and loadability.

Location and siz

Presented a clustering technique-based methodology for identifying the optimal size, location, and year of installing energy resources into a system.

Proposed a method to identify the optimal sizes of the energy storage system in order to mitigate the negative impact of penetrating wind energy into power systems. The method takes into consideration failures of Wind Turbine

Generators, the wind power uncertainty, wind speed temporal resolution, and correlation with the load.

Proposed a methodology for determining the adequate transmission system upgrades and size of the energy storage which are required for delivery of the wind generation

Composite Energy Storage and Wind Generation

System With Adequate Transmission Upgrades.

Presented a reliability-based methodology for grid

expansion planning of wind power integrated system

considering the uncertainties of lines and generators, and

Reliability-Based Grid Expansion Planning of Power

Systems Considering Wind Turbine Generators.

Incorporating Large-Scale Distant Wind Farms in

Probabilistic Transmission Expansion Planning

[118]

Reliability evaluation of restructured power systems

using a novel optimal power-flow-based approach.
Expansion planning

\section{Presented a theory and algorithm for a Transmission}

Expansion Planning method aiming to mitigate the negative impact of wind farms on the congestion cost and risk costs of a power system.

Proposed an approach to evaluate load point reliability in restricted power systems taking into consideration the effect

of wind power integration. Developed equivalent multistate models generation and transmission system. 
Table 2. Cont.

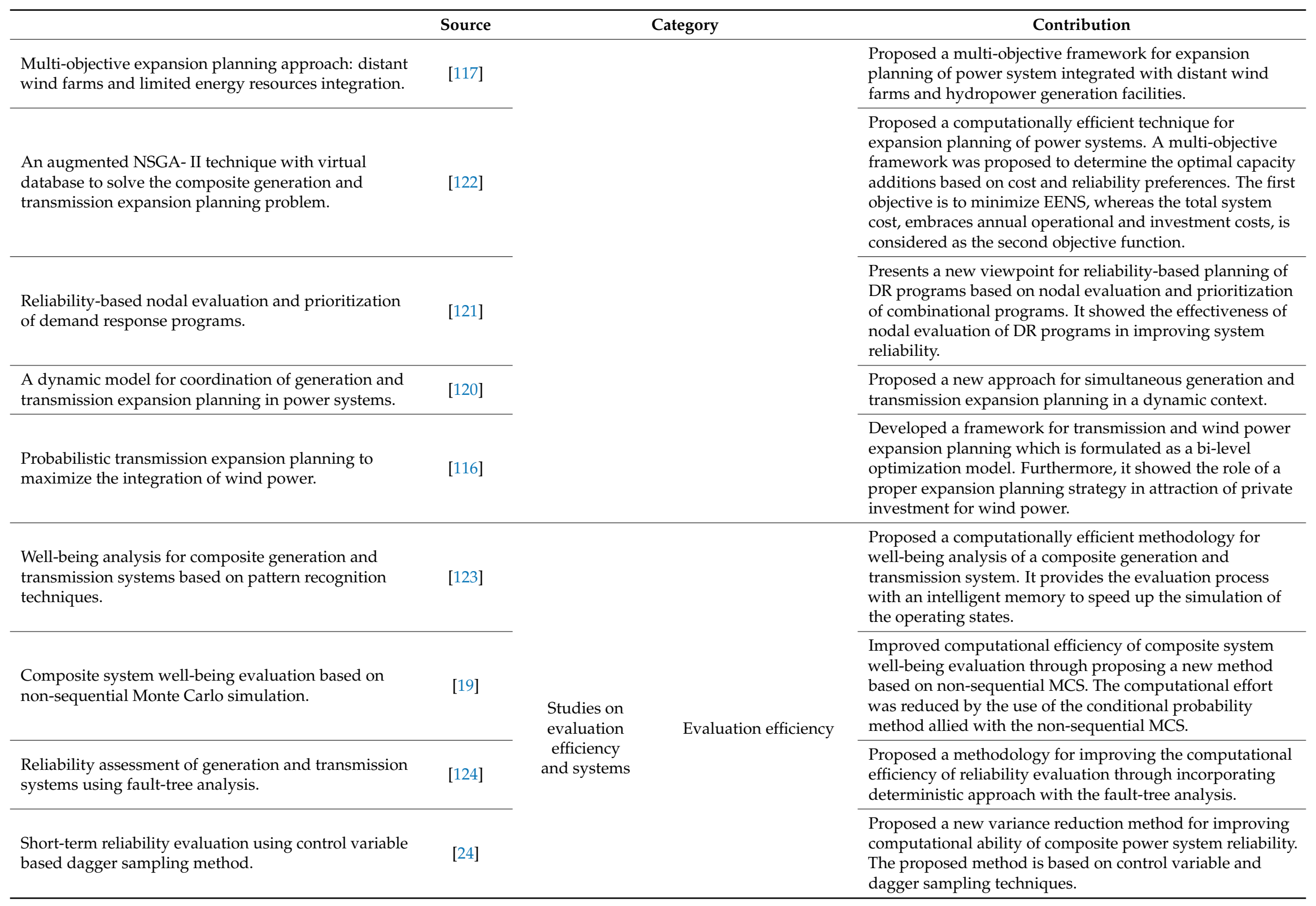


Table 2. Cont

\begin{tabular}{lc}
\hline & Source \\
\hline $\begin{array}{l}\text { State-space partitioning method for composite power } \\
\text { system reliability assessment. }\end{array}$ & {$[33]$} \\
\hline $\begin{array}{l}\text { Reliability Evaluation of Composite Power Systems } \\
\text { Using Markov Cut-Set Method. }\end{array}$ & {$[129]$} \\
\hline $\begin{array}{l}\text { Composite power system reliability evaluation using } \\
\text { modified minimal cut set approach. }\end{array}$ & [128] \\
\hline
\end{tabular}

Category

Contribution

Composite Reliability Evaluation Using Monte Carlo Simulation and Least Squares Support Vector Classifier.

33]

129]

\section{8]}

Adequacy equivalent development of composite generation and transmission systems using network screening.

Modified SPEA2 for Probabilistic Reliability

Assessment in Smart Grids.

[8]

Techniques for improving precision and construction efficiency of a pattern classifier in composite system reliability assessment.

Composite Power System Vulnerability Evaluation to Cascading Failures Using Importance Sampling and Antithetic Variates.

Composite Systems Reliability Evaluation Based on Monte Carlo Simulation and Cross-Entropy Methods.
[144]
Proposed a new method that compliments Variance

Reduction Techniques for further acceleration of sampling

low probability states. It can be combined with DC or AC

power flow or other analysis tool.

Proposed a DC-OPF Markov cut-set method for accelerating the evaluation of composite power system reliability taking into consideration the dependence of components introduced by fluctuating weather.

Improved the computational efficiency through developing a new minimal cut set method. It demonstrated high applicability in large scale systems and less computational effort.

Explored a hybrid computationally efficient method by combining MCS and the least squares support vector machine classifier. It can pre-classify the system states into success or failure states. Thus, the computational effort can

be reduced by performing the adequacy analysis for the failure states only.

Presented an approach to develop an adequacy equivalent of a composite system using network screening. It

determines the adequacy equivalent of the external area in order to facilitate extensive reliability studies in the study area.

Proposed a new multi-objective meta-heuristics method for improving the efficiency of probabilistic reliability

evaluation. The proposed method showed superiority in reducing computational effort and satisfying the accuracy.

Presented a new technique for improving the precision and construction efficiency of a classifier utilized in reliability evaluation which can be used to improve computational efficiency.

Proposed a new method based on Importance Sampling and Antithetic Variates techniques to evaluate cascading failures in a composite system reliability. The number of samples is noticeably reduce.

Proposed a new methodology that combines a

Cross-Entropy technique and MCS in order to accelerating the evaluation of composite power system reliability. 
Table 2. Cont.

\begin{tabular}{|c|c|c|c|}
\hline & Source & Category & Contribution \\
\hline $\begin{array}{l}\text { Eliminating Redundant Line Flow Constraints in } \\
\text { Composite System Reliability Evaluation. }\end{array}$ & [138] & & $\begin{array}{l}\text { Developed a methodology to eliminate redundant line flow } \\
\text { constraints in order to simplify optimal power flow } \\
\text { conducted for the failure states. Thus, the evaluation of } \\
\text { failure states can be accelerated }\end{array}$ \\
\hline $\begin{array}{l}\text { Splitting Method for Speedy Simulation of Cascading } \\
\text { Blackouts. }\end{array}$ & [139] & & $\begin{array}{l}\text { Developed a simulation technique based on the splitting } \\
\text { method for improving the simulation of cascading } \\
\text { blackouts. It enables rapid and practical computation of } \\
\text { large blackout probabilities. }\end{array}$ \\
\hline $\begin{array}{l}\text { Intelligent state space pruning for Monte Carlo } \\
\text { simulation with applications in composite power } \\
\text { system reliability. }\end{array}$ & [125] & & $\begin{array}{l}\text { Developed a new algorithmic method for improving } \\
\text { computational efficiency of MCS by intelligently and } \\
\text { efficiently pruning the state space. }\end{array}$ \\
\hline $\begin{array}{l}\text { Adaptive sequential importance sampling technique } \\
\text { for short-term composite power system adequacy } \\
\text { evaluation. }\end{array}$ & [65] & & $\begin{array}{l}\text { Proposed a novel adaptive importance sampling technique } \\
\text { for accelerating the short-term sequential reliability } \\
\text { evaluation of composite power systems. }\end{array}$ \\
\hline $\begin{array}{l}\text { A new formulation for power system reliability } \\
\text { assessment with AC constraints. }\end{array}$ & [132] & & $\begin{array}{l}\text { Approximated the AC power flow to formulate a linear } \\
\text { power flow model which is capable of taking both active } \\
\text { and reactive powers into account in reliability evaluation of } \\
\text { composite power systems. }\end{array}$ \\
\hline $\begin{array}{l}\text { Extracting Rare Failure Events in Composite System } \\
\text { Reliability Evaluation Via Subset Simulation. }\end{array}$ & [140] & & $\begin{array}{l}\text { Proposed a framework for reliability evaluation of } \\
\text { composite power systems with subset simulation. The } \\
\text { states with significant contribution to reliability indices } \\
\text { were extracted to accelerate the simulation. }\end{array}$ \\
\hline $\begin{array}{l}\text { Power system reliability evaluation using a state space } \\
\text { classification technique and particle swarm } \\
\text { optimisation search method. }\end{array}$ & [126] & & $\begin{array}{l}\text { Introduced a new state space classification technique based } \\
\text { on intelligent particle swarm optimization. It aims to } \\
\text { speeding up the reliability evaluation through classifying } \\
\text { the system states into success, failure, and unclassified } \\
\text { subspaces without performing power flow analysis. }\end{array}$ \\
\hline $\begin{array}{l}\text { Application of Bayesian networks in composite power } \\
\text { system reliability assessment and reliability-based } \\
\text { analysis. }\end{array}$ & [133] & & $\begin{array}{l}\text { Proposed a new computationally efficient methodology to } \\
\text { apply Bayesian Networks to composite power system } \\
\text { reliability studies. }\end{array}$ \\
\hline
\end{tabular}


Table 2. Cont

\begin{tabular}{|c|c|c|c|c|}
\hline & Source & \multicolumn{2}{|r|}{ Category } & Contribution \\
\hline $\begin{array}{l}\text { A Time-Dependent Approach to Evaluate Capacity } \\
\text { Value of Wind and Solar PV Generation. }\end{array}$ & [27] & & & $\begin{array}{l}\text { Improved the computational efficiency of the reliability } \\
\text { evaluation by applying Fuzzy C-mean clustering algorithm } \\
\text { to create a time-dependent model for wind power, solar } \\
\text { generation, exchanged electricity, and load data. }\end{array}$ \\
\hline $\begin{array}{l}\text { A Continuous Time Markov Chain Based Sequential } \\
\text { Analytical Approach for Composite Power System } \\
\text { Reliability Assessment. }\end{array}$ & [5] & & & $\begin{array}{l}\text { Reduced the computational effort of reliability evaluation } \\
\text { by improving a continuous time Markov chain based } \\
\text { sequential analytical approach. The new approach merges } \\
\text { all high order contingencies into a single state, which can } \\
\text { then be analyzed by MCS. }\end{array}$ \\
\hline $\begin{array}{l}\text { Improved Importance Sampling for Reliability } \\
\text { Evaluation of Composite Power Systems. }\end{array}$ & [131] & & & $\begin{array}{l}\text { Improved the computational efficiency of reliability } \\
\text { evaluation through introducing Cross- Entropy based } \\
\text { Monte Carlo simulation. This systematic method aims to } \\
\text { find an optimal way of sampling load states, generation, } \\
\text { and transmission line outages in order to minimize the } \\
\text { computational effort. }\end{array}$ \\
\hline $\begin{array}{l}\text { Fast reliability evaluation method for composite } \\
\text { power system based on the improved EDA and } \\
\text { double cross linked list }\end{array}$ & [134] & & & $\begin{array}{l}\text { Improved a new MCS approach in terms of computation } \\
\text { and accuracy. The state pruning was accelerated by the } \\
\text { improved estimation of distribution algorithm and double } \\
\text { cross linked list. }\end{array}$ \\
\hline $\begin{array}{l}\text { Quasi Monte Carlo method for reliability evaluation of } \\
\text { power system based on Dimension Importance } \\
\text { Sorting. }\end{array}$ & [136] & & & $\begin{array}{l}\text { Presented a non-sequential quasi MCS approach based on } \\
\text { Dimension Importance Sorting. The proposed approach } \\
\text { demonstrated computational efficiency and accurate } \\
\text { indices. }\end{array}$ \\
\hline $\begin{array}{l}\text { A composite generation and transmission reliability } \\
\text { test system for research purposes. }\end{array}$ & [141] & & Evaluation test systems & $\begin{array}{l}\text { Presents a reliability test system for research purpose. It is } \\
\text { developed based on a real HV network in a province } \\
\text { located in Iran. }\end{array}$ \\
\hline $\begin{array}{l}\text { Review of reduction techniques in the determination } \\
\text { of composite system adequacy equivalents. }\end{array}$ & [142] & & Computation & $\begin{array}{l}\text { Presented a review of the reduction techniques which are } \\
\text { directly or indirectly related to the reliability evaluation of } \\
\text { composite power systems. }\end{array}$ \\
\hline $\begin{array}{l}\text { Adequacy Assessment Considerations in Wind } \\
\text { Integrated Power Systems. }\end{array}$ & [143] & Review articles & Modeling approaches & $\begin{array}{l}\text { Presented some of important factors and procedures that } \\
\text { need to be considered when conducting reliability } \\
\text { evaluation of wind power integrated system. It reviewed } \\
\text { the considerations regarding wind speed data models, } \\
\text { selecting the required data, wind energy conversion system } \\
\text { models and their application. }\end{array}$ \\
\hline
\end{tabular}


Eighty-two studies used educational purpose test systems, as shown in Figure 5. Only 26 adopted real test systems, and several used both categories of test systems. Eighty-seven studies used the reliability test system (RTS) and the Roy Billinton test system proposed by Billinton in 1979 [145] and 1989 [146], respectively.

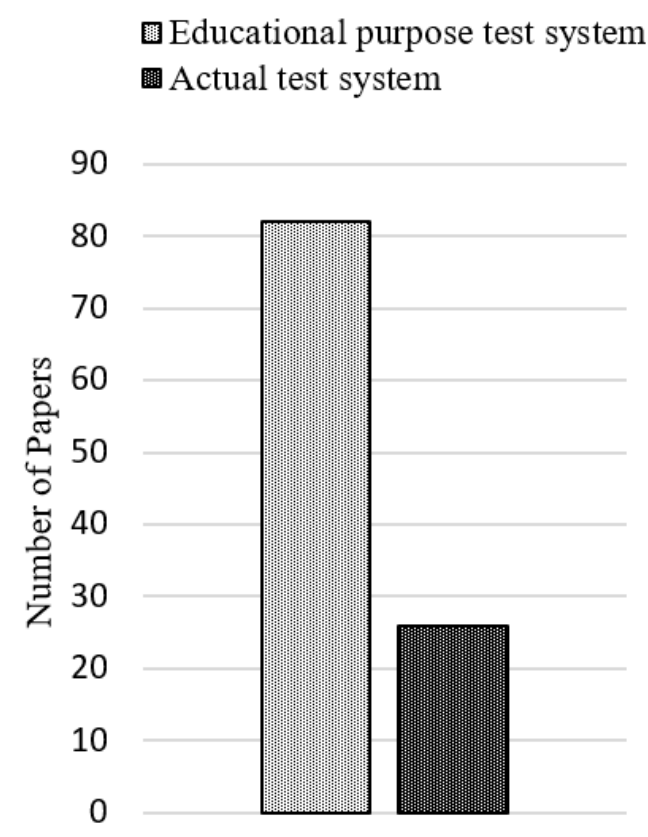

Figure 5. Category of the test systems used in literature.

The literature was categorized based on the location of the first author's university to illustrate the regional distribution of the studies, as shown in Figure 6. HL2 reliability studies received more attention in Asia than in the combination of other regions, which indicates a tendency of increased interest in this topic in Asia. Iran (27/100) devoted the most attention, followed by the United States of America (19/100).

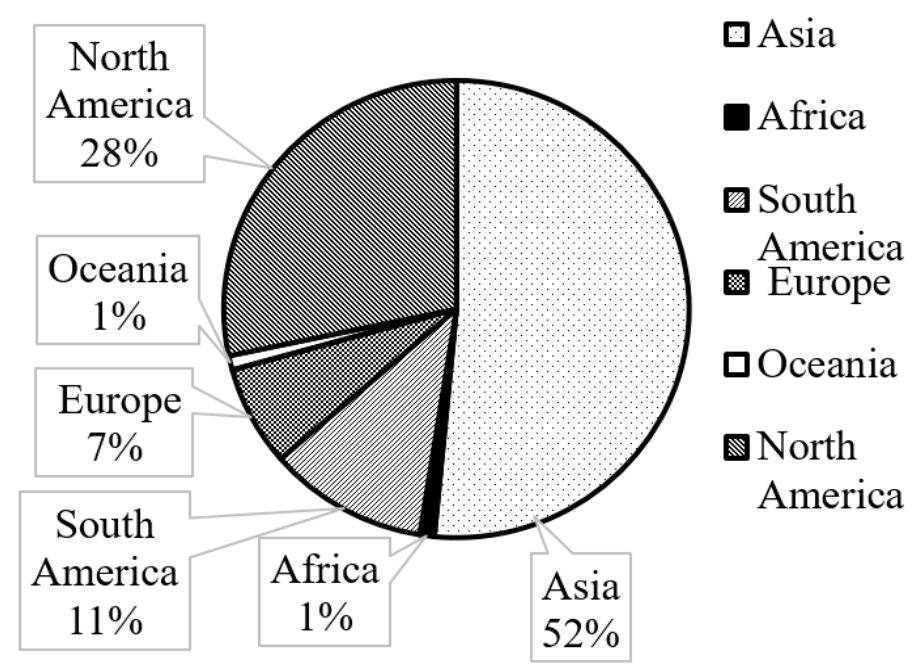

Figure 6. Regional distribution of the studies.

Researchers focused on renewable energy resources, and 31 out of 100 articles investigated power systems integrated with renewable energy resources. Twenty-six of 31 articles focused on wind power integration, and the remaining focused on the combination of wind power with hydro or solar power technologies, as shown in Figure 7. These articles are categorized in Figure 8 according to latitude. 


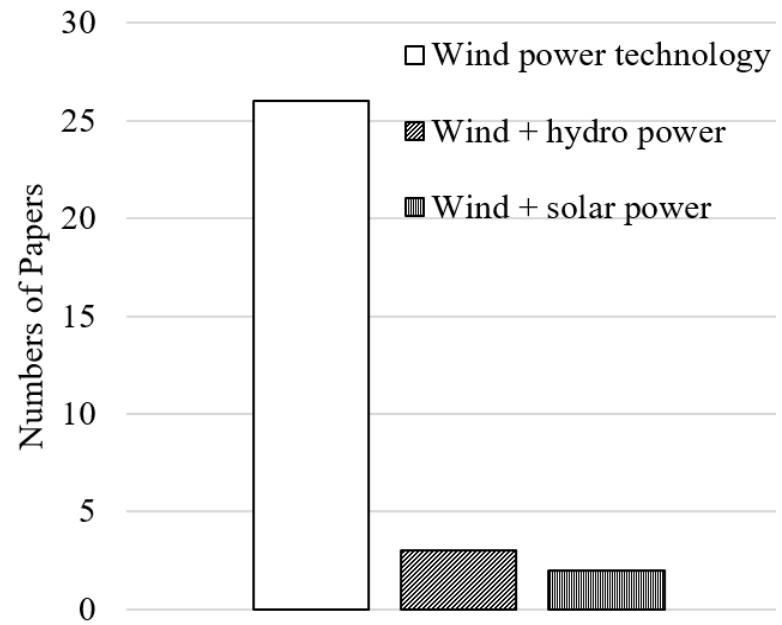

Figure 7. Consideration of renewable energy resources in the studied literature.

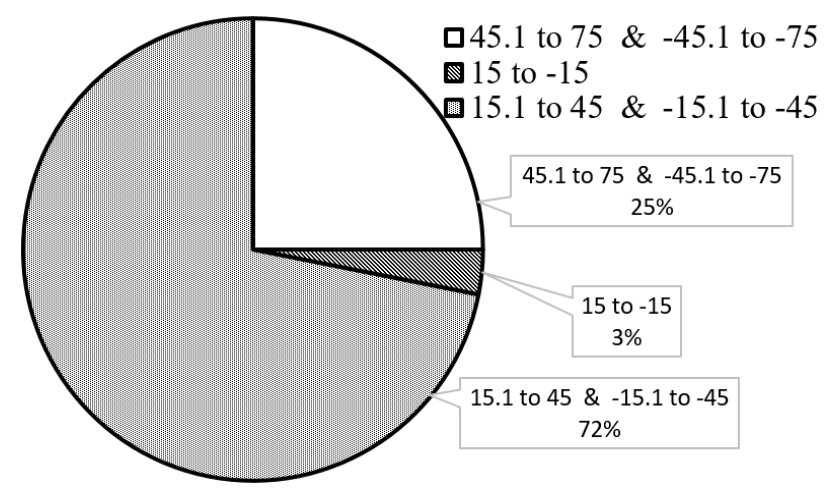

Figure 8. Categorization of the articles that focused on renewable energy resources according to the authors' location.

To achieve deep insights into the literature, the following sections were written to emphasize the motivations behind the reliability studies on HL2, the challenges that the researchers attempted to address, and the recommendations for improving this research area.

\subsection{Motivations}

The increase in electricity dependence has led to remarkable developments in the power industry. The structural changes that recently occurred in this industry sent a clear signal to planners and operators about the urgent need to develop a reliability evaluation process that matches recently developed power systems [107]. Therefore, HL2 reliability evaluation is considered a promising research area. For a systematic discussion, this section classifies the studied literature into categories according to the motivations that stimulated the researchers to focus on this field.

\subsubsection{Motivations Related to Matching Reality}

The first step in reliability studies is to model individual components [147]. Accurate reliability indices can be achieved by obtaining many realistic models of the system. Therefore, matching reality is a critical motivation that can mainly be accomplished by considering uncertainty and other parameters.

Modeling of weather conditions, such as hurricanes, in reliability studies has led to numerous realistic indices [80]. However, considering weather conditions adds complexity to the evaluation process. This situation serves as a motivation to propose an evaluation approach that can handle this complexity [129]. In the case of renewable energy reliability studies, the researchers were compelled to consider weather conditions [66,91]. Evaluation approaches were proposed in $[28,132]$ 
to present realistic indices by considering AC constraints in the reliability evaluation. Moreover, system constraints can be expanded to contain emission constraints [81].

Increased reliance on technology to control and monitor power systems refutes the assumption of ignoring these components. The control and monitoring system must be considered to obtain realistic results $[10,79,83]$. Dynamic analysis, apart from static analysis, should be performed to effectively assess reliability [9]. A comprehensive model is required in expansion planning. Hence, a dynamic analysis was presented in [120]. The other parameters that were considered to maintain an adequate level of reality were cascading failures [139] and protection system failures [84].

Uncertainty is a common characteristic of most physical components in power systems in reality. Another set of articles considered the uncertainty of input data to make the results close to reality [1]. Considerable realistic findings were obtained based on fuzzy theory [85] and the Bayesian network model [133].

The increased installation of renewable power resources has emphasized the importance of incorporating these resources into reliability evaluation [67]. This type of power sources is characterized by a high degree of intermittency [88]. Therefore, realistic models should be constructed to appropriately represent them in reliability evaluation $[27,118,119]$.

\subsubsection{Motivations Related to New Technology}

Increased electricity demand requires the installation of new transmission systems. FACTS, which is an attractive area of development, was introduced to avoid the installation of new transmission lines [73]. Although this device consists of inexpensive and low-rated power components, it can control the main transmission parameters, such as line impedance, voltage, and power angle [74]. However, the effect of various FACTS devices on composite power system reliability has not been addressed adequately [101].

The hardwired architecture of power systems has been gradually replaced by communication networks and computer systems [78]. Assuming a reliable cyber system in the planning phase is no longer precise [77]. Investigation conducted on large scale blackout in power systems have revealed the critical role of information at control centers. Some outages might be avoided or significantly reduced if more complete information was provided through establishing sufficient telecommunication system [79]. A combination of power application security and supporting infrastructure security is required to be included in risk assessment process [148].

Optimal preventive maintenance planning requires the optimization of the overall cost and system reliability. Energy storage systems have recently emerged as an essential part of modern power grids. A probabilistic optimization framework is required to balance reliability while reducing the operation cost [32]. DR is another tool to enhance system reliability. Utilities apply this technology to avoid necessary investments while adhering to the increasing environmental concerns [121].

\subsubsection{Motivations Related to Reliability Enhancement}

The reliability of power systems has experienced many challenges, especially after the remarkable developments in this sector and the growing energy demand. Reliability enhancement is a critical duty of system planners and operators. They need to adequately ensure system reliability under operation system pressures, which can be implemented via system reliability evaluation [7]. Several researchers have proposed a maintenance plan to improve system reliability. The authors of [110] improved system reliability and minimized the operation cost by using an optimal maintenance plan for the system's circuit breakers. Others achieved this target by improving a cost-effective replacement plan [111,112]. Supporting a transmission system with FACTS devices is also a promising strategy to improve system reliability, as shown in $[26,74,101]$. References $[20,75,93]$ investigated transmission lines equipped with DTR to support system reliability. Reliability enhancement of wind integrated systems can be accomplished by optimal planning of energy storage $[30,114]$. Studies have also been conducted on DR programs to improve power system reliability [86,121]. 


\subsubsection{Motivations Related to Power System Development}

Keeping pace with the increasing developments in power system architecture and equipment is another motivation for the improvement of reliability evaluation tools. The increase in the scale of modern power systems stimulates actions to improve simulation efficiency and overcome computational burdens. Many studies reduced simulation time to facilitate reliability evaluation of large-scale applications $[17,19,124,126,132,139,140,149]$.

The development in power systems is not limited to system scale and structure. Renewable energy integration is a common phenomenon in modern power systems. Therefore, other researchers focused on wind power to handle uncertainty [69,105], expansion planning [70,114,118,119], and transmission line reinforcement [106,107].

In a restructured power system, many players are assigned to serve the customers [8]. This condition increases the degree of system uncertainty. Moreover, the decisions made by these players remarkably affect the reliability of the power system [100]. These players should recognize the implications of their decisions and assets on system reliability [90]. However, this competitive environment makes price, quality, and reliability of the delivered energy important factors to both customer and supplier [150].

The effectiveness and advantages of smart grid applications have also attracted the attention of researchers [92]. The cyber-physical interface is the key advantage of smart grids, which provides a robust control system [83]. Cyber-induced dependent failures should be considered in HL2 reliability evaluation [77].

\subsubsection{Motivations Related to the Needs of Customers, Planners, and Decision Makers}

Customers have different valuations of service quality and tend to balance price and reliability to suit their needs. Restructured power systems give value to a customer's choice and makes him a crucial player in the system [100]. This condition improves the service quality and encourages electricity enterprises to improve their system efficiency [90]. Reference [42] planned a spinning reserve to satisfy the reliability level required by customers.

Frequency and duration indices are more natural than other common indices for system operators [151]. These indices result in effective system evaluation, but they require additional adequacy analyses, which considerably increases the computational time [19]. By contrast, indices for the probability distributions of systems provide decision makers with considerable information and practical insights [95].

Short-term reliability evaluation has recently emerged as a beneficial tool in modern applications. DR programs are applied for a limited number of times over a year or month. Therefore, short-term assessment is highly effective [86]. Short-term assessment can also be used to evaluate system states before a large blackout occurs [24]. Component criticality is another important input for planners and decision makers when planning for maintenance, operation, and investment [111].

\subsection{Challenges}

With the rapid growth of the demand for power, electricity has become a global critical issue. Many challenges have been encountered with the development of this sector. Thus, power system reliability has attracted considerable concern. Many challenges associated with HL2 reliability were addressed by the authors of the surveyed articles. This SLR discusses the reported challenges combined with the citation of relevant references to which the readers can refer for further discussion. The challenges are categorized into a few sets, as shown below.

\subsubsection{Challenges Related to Realistic Evaluation}

Analyzing system operations and obtaining an appropriate model are the main steps used in reliability evaluation [73]. A system reliability model should match reality to obtain accurate 
results. A realistic model requires much effort combined with a large amount of historical data [152]. The integrity of a decision adopted during planning or operation stages is highly affected by model accuracy [20]. Therefore, perhaps the most persistent and crucial challenges are those related to the reality of the proposed model. This condition is evident because a large number of the surveyed studies focused on achieving a highly realistic and accurate model.

Many realistic indices can be achieved by considering the possible parameters that affect system performance. For example, weather condition remarkably affects the components $[80,129]$. The load model also affects the accuracy of indices [4]. References [28,132] handled AC constraints to improve the accuracy of outcomes.

Cascading failure is a common phenomenon in many infrastructure networks, such as power systems [152]. Modeling of cascading failures leads to highly accurate indices [135]. Many important factors, such as substations $[9,10]$ and protection systems $[22,84,110]$, should be considered in reliability evaluation. Other models, such as cyber systems [77-79,83], wind power generation [66], and DTR systems [20], should be improved to match reality.

Uncertainty is a serious challenge that should be addressed to improve model efficiency. Conventional reliability evaluation methods are unsuitable for renewable energy resources due to their intermittency and uncertainty [27]. Several researchers integrated uncertainty with power system parameters to obtain accurate load models $[82,85]$ and renewable power resources $[69,105,119]$. The correlations among the system parameters were considered to obtain an accurate evaluation $[88,91]$.

\subsubsection{Challenges Related to Computational Cost}

Computational complexity is an obstacle to the extensive practical application of reliability evaluation [33]. The increase in power system scale reveals the intensive complexity of HL2 reliability studies and the criticality of computational capabilities.

Although well-being analysis is valuable, it requires additional analyses that considerably demand extensive computational efforts [19]. Efficient methods for performing this analysis were created to make it suitable for large-dimension systems [123].

The number of system states exponentially increases with the power system dimension, resulting in a highly complex and time-consuming evaluation [132]. Researchers handled this issue by adopting several techniques, such as variance reduction, sampling, and network reduction $[17,24,26,65,135,137]$.

Rapid developments in the power system structure pose a major challenge to researchers and planners in this sector. A modified minimal cut-set approach was proposed in [128] to overcome the computational complexity resulting from handling large scale power systems. Smart grid technology increases the amount of computational burden due to the diversity of energy resources and communication and control systems [8]. Considering the restructured power system requires many computational capabilities because numerous players join the system [90]. The growing interest in renewable energy resources has forced researchers and planners to consider them in the reliability evaluation. However, these resources are normally unpredictable and intermittent, which increases the computational effort required to obtain an acceptable level of accuracy $[27,67]$.

A trade-off between detailed modeling and computational cost have formed a controversial issue discussed by some authors. Although considering time-varying elements (such as wind, load, and river inflows) in reliability evaluation produces accurate findings, high computational cost is required [89]. Cascading failures is another factor that should be minutely modeled in order to study large-scale blackout. However, it requires additional system states to be simulated. This issue was discussed in [135]. The more reliable the power system is, the smaller the probability of system failure is [136]. Sequence of rare failures could lead to large blackout in a composite power system [139]. Moreover, an exhaustive computation of detailed modelling for all possible combinations of failures is complicated. This phenomena was discussed in [135,139]. In [72], transmission system model was 
improved through incorporating line switching operations. However, complexity and uncertainty made analysis of the power system more challenging.

\subsubsection{Challenges Related to the Economic Aspect}

Several HL2 reliability evaluation studies aimed to mitigate the operation and upgrading costs of power systems. The continuous expansion of power grids requires considerable development in transmission systems. However, the installation of new transmission lines is not economically feasible [73]. Thus, several researchers overcame this excessive cost by introducing measures and validating them using reliability evaluation $[71,73,74,93,113]$.

The cost of maintenance procedures is considerably high when improperly managed. Several researchers have proposed new strategies to enhance the cost efficiency of maintenance and mitigate excessive expenditures while maintain efficient system functions [111]. References [47,48] investigated and optimized the validity of several strategies. The number of spare units is an issue to the utility of power systems. The costs of holding spare equipment should be balanced with the required reliability level [97].

Energy storage is a technology to enhance renewable energy integration. However, its cost is still a major obstacle to its wide adoption [32]. Optimization techniques were proposed to obtain the right balance between energy storage system expenditure and reliability.

\subsubsection{Challenges Related to System Deficiency}

Several factors reduce the reliability of power systems. A satisfactory degree of reliability is essential in planning and operation phases. The high penetration level of renewable sources jeopardizes system stability due to the intermittency and uncertainty of these sources [70]. During high-power generation, a waste of renewable energy occurs, and low renewable power production makes the system fragile [107]. Therefore, persistent development of the system structure and control is required to adapt to the increasing emergence of intermittent power resources [70]. The optimal site, size, and installation year of these resources should be systematically identified [115].

The introduction of modern power systems requires that a cyber-system must be extensively dealt with because it is an essential component of smart grids. An attacker could intrude into control and communication systems and disturb the service by exploiting the vulnerabilities of the cyber system. The inevitable increase in cyber system dependence leads to many vulnerabilities [76].

The transmission system plays a crucial role in bulk system planning, operation, and maintenance practices [153]. Electricity demand has exponentially increased, and electricity generation is installed in locations that are distant from intensive load areas. The installation of intermittent renewable energy has spread widely. All of these conditions make the transmission system fragile and present a critical challenge to system reliability $[26,74,101,107]$.

\subsection{Recommendations}

The important recommendations mentioned by the researchers of the studied literature are summarized. This section aims to mitigate the challenges encountered by researchers, planners, and decision makers in the HL2 reliability area.

\subsubsection{Recommendations to Researchers}

The application of HL2 reliability evaluation is limited in practical power due to the challenges mentioned in Section 5 [84]. The considerable development of power system structure and scale should be matched by an improvement in the tools and processes of reliability evaluation. Thus, recommendations were provided in line with the literature in this area. The recommendations were assigned to improve the reliability evaluation and achieve two main purposes, namely, suitability in practical applications and synchronization with recent developments in composite power systems. Moreover, the impact of different parameters on HL2 reliability was emphasized. 
Remarkable effort was exerted to accelerate the evaluation and thus support the reliability evaluation of large-scale systems. High computational efficiency can be achieved by combining various techniques, such as network reduction with pattern recognition [123] and state-space partitioning with variance reduction [33]. A combination of intelligent state-space pruning and sequential MCS need to be investigated to determine time-dependent parameters, such as renewable energy resources [134]. The subset simulation based method presented in [140] could be improved to include chronological simulation and obtain area and bus indices.

Although several researchers proposed fast methods, they considered other input variables, such as reactive and voltage constraints $[25,98]$. Moreover, dynamic assessment is important to guarantee system stability [70]. A comprehensive model of several system components, such as protection systems, should be developed to obtain realistic results [84]. Many items can be added to the proposed HRTS in [141] to enrich its database.

Several of the investigated studies did not consider a number of influential factors. Economic evaluation of energy storage operation in wind integrated power systems should be considered to obtain accurate outcomes [114]. Market design and locational incentives should also be considered in wind power integration [68]. Further reliability improvement was targeted by other researchers, and the reliability obtained by DTR system installation in [93] can be improved by coupling with DSM or FACTS.

Several studies in the investigated literature proved that FACTS devices can remarkably improve system reliability. However, other types of FACTS devices should be considered for wider insight [26]. Reliability analysis of systems that combine different FACTS controllers is also required [73]. Wind power is the most common renewable energy source investigated in HL2 reliability studies. However, other renewable sources (e.g., photovoltaic) have different outcomes and should be considered $[89,107,116]$. Cyber-attack scenarios should be investigated under different renewable energies [76].

A comparison study provides decision makers with a detailed discussion of several options. The performance of various energy storage technologies in wind integrated power system should be differentiated $[114,143]$. Accurate insights can be obtained by using estimated indices that consider voltage and reactive power constraints, and RTS indices can be evaluated to serve as a benchmark for future work [28]. A Bayesian network model can also be used to compare various protection system scenarios [84].

Most of the studies were implemented based on test systems for educational purposes. Most of these systems were designed a long time ago and do not fit modern power systems. Thus, several researchers repeated their work on ready-made or commercial power system reliability $[17,110,137]$. Several of the methodologies presented in literature are also applicable to other systems, such as distribution systems [80].

\subsubsection{Recommendations to Planners and Operators}

The outcomes of the studies were summarized by the researchers to fit real-life conditions. Valuable recommendations were given by the researchers to be followed by planners and operators. They can help reflect the researchers' effort on real applications.

Several studies proved the effectiveness of using a certain technology with regard to system reliability and provided encouragement to adopt these technologies. For example, an HVDC transmission system that incorporates a voltage-sourced converter tapping station can remarkably improve the reliability indices at the load point [71]. Distributed static series compensators, which are FACTS devices, are recommended to be installed in transmission systems [74]. The optimal setting and control mode of UPFC are verified to be applicable to real-life systems [101]. The storage system has a positive effect on the wind integrated power system [32,92]. DTR is another technology that supports transmission capacity under an intermittent power source and enhances HL2 system reliability [93]. A high reliability level can be achieved by integrating DTR with other technologies, such as DSM 
or storage system. The results of [72] can be used as a guide in the actual applications of line switching operations.

Several researchers stated that a number of parameters should be considered in the planning phase to achieve high accuracy. The impact of information infrastructure on reliability is indisputable and need to be included in HL2 reliability studies [79]. The availability of wind turbines has an impact on wind farm output and system reliability [67]. The inclusion of emission constraints leads to accurate informative reliability evaluation [81].

Planners and operators are also recommended to apply the proposed methodologies presented in literature in real applications. The methodology proposed in [119] can be adopted for grid expansion planning of HL2 power systems integrated with a wind power farm. The probability distribution functions of reliability indices provide a clear interpretation of these indices [95]. A new method for probabilistic reliability evaluation with multi-objective meta-heuristics provides an accurate evaluation with reduced computational effort for planners [8]. Reference [122] accelerated HL2 reliability evaluation to fit large composite systems in real applications. The authors of [128] recommended their new minimal cut set method to be used for accelerating the reliability evaluation of large scale composite power system. Another methodology presented in [107] can be applied to transmission planning when thermal units are replaced by intermittent sources.

For generation system expansion planning, planners can determine the optimal load allocation plan by using the approach presented in [90]. Multiple correlations and uncertainty should be included to obtain highly accurate results, especially in renewable power sources $[86,88,91]$. Although the consideration of multiple correlations results in increased computational burden, several researchers proposed efficient computational methods [27]. Better planning decisions can be taken if aging and loading effects are considered in DTR system planning [20].

\subsubsection{Recommendations to Decision Makers and Authorities}

The provision of reliable service to customers is a challenge to utility. Decision makers and authorities are responsible for ensuring the quality and reliability of power systems. Many researchers provided suggestions to maintain the development in this sector.

Network design standards and regulations need to be improved and updated because conventional power systems continually move toward the smart grid paradigm $[93,106]$. Decision makers are required to select a suitable energy policy based on renewable energies [117].

System reliability analysis is an effective process to provide decision makers with detailed insights into the feasibility and benefits of a project. The complications of modern power systems demonstrate the urgent need to follow state-of-the-art procedures for evaluating power system reliability with regard to renewable energy integration [68], cyber system [76], maintenance [108], load management [87], transmission system [20,71], and protection system [22]. Component criticality is an important input to the decision-making stage in investment operational planning and maintenance [99].

\section{Conclusions}

\subsection{Synthesis of Findings}

Power has become a global concern due to the growing population and the increase in technology dependence caused by the modern technology revolution. From customers' point of view, the provision of continuous electricity service is indisputable. Therefore, literature shows the importance of reliability evaluation in assuring a reliable power supply. Although research on reliability evaluation of composite power systems has been active since the 1960s, the applications of this topic in real life are still limited.

The main contribution of this SLR is the provision of comprehensive insights into the literature. This approach offers valuable knowledge about the trends of published works conducted on reliability studies on composite power systems. It helps the future scholars to precisely identify the gaps in this area. The literature shows four main categories in terms of contributions; investigation 
studies, planning and optimization studies, evaluation efficiency and systems studies, and review articles. Motivations, challenges, and recommendations mentioned in the literature are highly diverse, which demonstrated considerable ramification in this topic.

The literature demonstrates that some specific domains (e.g., computational efficiency and wind power) received attention more than others (e.g., realistic test systems and solar power). Moreover, there is lack of review articles that summarize and analyze relevant findings. Another obvious trend, most of the researchers apply their study on educational purpose at the expense of realistic applications.

Most of the researchers used educational purpose test systems proposed in 1979 and 1989. Nevertheless, our review found that these systems operate according to North America power grids. They are not equipped with modern technologies. This compelled researchers to individually modify the systems which led to inconsistent results. Considering the urgent requirement for realistic and modern test systems, only one article proposed a new test system based on a real HV network in the south of Iran. However, this system lacks some items and data that can be required for future studies.

This SLR also finds that considerable effort was devoted to reduce the computational burden at the expense of accuracy. Acceleration of the evaluation process was a critical issue in the beginning of computer capabilities. It is recommended by some authors to focus on obtaining accurate and realistic indices rather than worrying about computational abilities.

Another obvious trend is related to reliability studies on power systems integrated with renewable energy resources. Wind power elicited the most attention, whereas other types of renewable energy resources were nearly ignored. This condition is due to the location of the researchers. Most of the researchers conducted their studies in universities located between the latitude $15^{\circ}$ and $75^{\circ}$ where wind power is the most common renewable energy source. This condition could be a motivation to countries located around the equator to focus on the reliability of solar power integrated systems.

The survived literature showed that Asia is the leading continent in reliability evaluation, accounting for more than half of the studies (52/100). This finding indicates increased interest in the topic in Asia, whereas the interest in Europe is diminished. This condition reflects the new rising regions in the power industry (e.g., Iran conducted more than a quarter of the studies, i.e., 27/100).

\subsection{Limitation}

The most pertinent limitations of this SLR are the number and identity of surveyed articles, although the selected sources of the articles are reliable and representative of a broad collection. Furthermore, the sample of published research on HL2 reliability does not necessarily reveal the reality of this field because several valuable efforts have not been published to the public for several reasons. For highly realistic insights, an SLR needs to cover reliability studies on HL1 and HL3.

Author Contributions: H.A. and H.J. collected corresponding references. J.T. and C.-M.L. revised and improved it, H.A. wrote it.

Funding: This work is funded by the USM external grant 304/PELECT/6050385.

Conflicts of Interest: The authors declare no conflict of interest.

\section{Nomenclature}

$\begin{array}{ll}\text { SLR } & \text { Systematic Literature Review } \\ \text { MCS } & \text { Monte Carlo Simulation } \\ \text { HL } & \text { Hierarchical Level } \\ \text { DSM } & \text { Demand-Side Management } \\ \text { DTR } & \text { Dynamic Thermal Rating } \\ \text { FACTS } & \text { Flexible AC Transmission Systems } \\ \text { WoS } & \text { Web of Science } \\ \text { SD } & \text { Science Direct } \\ \text { Q } & \text { Reactive power } \\ \text { V } & \text { Voltage }\end{array}$




$\begin{array}{ll}\text { MG } & \text { Microgrid } \\ \text { WAMS } & \text { Wide-Area Measurement System } \\ \text { IEC } & \text { International Electrotechnical Commission } \\ \text { UPFC } & \text { Unified Power Flow Controller } \\ \text { DR } & \text { Demand Response } \\ \text { DC } & \text { Direct Current } \\ \text { AC } & \text { Alternating Current } \\ \text { HVDC } & \text { High-Voltage Direct Current } \\ \text { DFIG } & \text { Doubly-Fed Induction Generator } \\ \text { IPFC } & \text { Interline Power-Flow Controller } \\ \text { VSC } & \text { Voltage Source Converter } \\ \text { SCADA } & \text { Supervisory Control and Data Acquisition } \\ \text { WORRIS } & \text { Web Based Online Daily Time Interval Reliability } \\ \text { NDLM } & \text { Integrated Information System } \\ \text { WTG } & \text { Wind Turbine Generator } \\ \text { EENS } & \text { Expected Energy Not Supplied } \\ \text { OPF } & \text { Optimal Power Flow } \\ \text { RTS } & \text { Reliability Test System }\end{array}$

\section{References}

1. Kumar, T.B.; Sekhar, O.C.; Ramamoorty, M.; Lalitha, S.V.N.L. Evaluation of Power Capacity Availability at Load Bus in a Composite Power System. IEEE J. Emerg. Sel. Top. Power Electron. 2016, 4, 1324-1331. [CrossRef]

2. Billinton, R. Composite System Reliability Evaluation. IEEE Trans. Power Appar. Syst. 1969, PAS-88, $276-281$. [CrossRef]

3. Billinton, R.; Allan, R. Reliability Evaluation of Engineering Systems Concepts and Techniques; Springer Science \& Business Media: New York, NY, USA, 2013; ISBN 1489906851.

4. Veliz, F.F.C.; Borges, C.L.T.; Rei, A.M. A Comparison of Load Models for Composite Reliability Evaluation by Nonsequential Monte Carlo Simulation. IEEE Trans. Power Syst. 2010, 25, 649-656. [CrossRef]

5. Hou, K.; Jia, H.; Xu, X.; Liu, Z.; Jiang, Y. A Continuous Time Markov Chain Based Sequential Analytical Approach for Composite Power System Reliability Assessment. IEEE Trans. Power Syst. 2016, 31, 738-748. [CrossRef]

6. Lotero, R.C.; Contreras, J. Distribution system planning with reliability. IEEE Trans. Power Deliv. 2011, 26, 2552-2562. [CrossRef]

7. Wang, Y.; Guo, C.; Wu, Q.H. A Cross-Entropy-Based Three-Stage Sequential Importance Sampling for Composite Power System Short-Term Reliability Evaluation. IEEE Trans. Power Syst. 2013, 28, 4254-4263. [CrossRef]

8. Mori, H.; Kakuta, H. Modified SPEA2 for Probabilistic Reliability Assessment in Smart Grids. Procedia Comput. Sci. 2011, 6, 435-440. [CrossRef]

9. Da Silva, A.M.L.; Violin, A.; Ferreira, C.; Machado, Z.S. Probabilistic Evaluation of Substation Criticality Based on Static and Dynamic System Performances. IEEE Trans. Power Syst. 2014, 29, 1410-1418. [CrossRef]

10. Martínez-lacañina, P.J.; De La Villa-jaén, A.; Martínez-ramos, J.L. Hybrid procedure including subtransmission systems and substations for reliability assessment. IET Gener. Transm. Distrib. 2013, 7, 1461-1472. [CrossRef]

11. Billinton, R.; Li, W. Reliability Assessment of Electric Power Systems Using Monte Carlo Methods; Physics of Solids and Liquids; Springer: New York, NY, USA, 1994; ISBN 9780306447815.

12. Kadhem, A.A.; Wahab, N.I.A.; Aris, I.; Jasni, J.; Abdalla, A.N. Computational techniques for assessing the reliability and sustainability of electrical power systems: A review. Renew. Sustain. Energy Rev. 2017, 80, 1175-1186. [CrossRef]

13. Wang, L.; Singh, C. Population-based intelligent search in reliability evaluation of generation systems with wind power penetration. IEEE Trans. Power Syst. 2008, 23, 1336-1345. [CrossRef]

14. Billinton, R.; Gao, Y. Multistate Wind Energy Conversion System Models for Adequacy Assessment of Generating Systems Incorporating Wind Energy. IEEE Trans. Energy Convers. 2008, 23, 163-170. [CrossRef] 
15. Bakkiyaraj, R.A.; Kumarappan, N. Optimal reliability planning for a composite electric power system based on Monte Carlo simulation using particle swarm optimization. Int. J. Electr. Power Energy Syst. 2013, 47, 109-116. [CrossRef]

16. Zhou, P.; Jin, R.Y.; Fan, L.W. Reliability and economic evaluation of power system with renewables: A review. Renew. Sustain. Energy Rev. 2016, 58, 537-547. [CrossRef]

17. Shu, Z.; Jirutitijaroen, P.; da Silva, A.M.L.; Singh, C. Accelerated State Evaluation and Latin Hypercube Sequential Sampling for Composite System Reliability Assessment. IEEE Trans. Power Syst. 2014, 29, 1692-1700. [CrossRef]

18. Greenwood, D.M.; Taylor, P.C. Investigating the Impact of Real-Time Thermal Ratings on Power Network Reliability. IEEE Trans. Power Syst. 2014, 29, 2460-2468. [CrossRef]

19. Amaral, T.S.; Borges, C.L.T.; Rei, A.M. Composite system well-being evaluation based on non-sequential Monte Carlo simulation. Electr. Power Syst. Res. 2010, 80, 37-45. [CrossRef]

20. Teh, J.; Lai, C.M.; Cheng, Y.H. Impact of the Real-Time Thermal Loading on the Bulk Electric System Reliability. IEEE Trans. Reliab. 2017, 66, 1110-1119. [CrossRef]

21. Jabir, H.J.; Teh, J.; Ishak, D.; Abunima, H. Impacts of Demand-Side Management on Electrical Power Systems: A Review. Energies 2018, 11, 1-19. [CrossRef]

22. Jiang, K.; Singh, C. New Models and Concepts for Power System Reliability Evaluation Including Protection System Failures. IEEE Trans. Power Syst. 2011, 26, 1845-1855. [CrossRef]

23. Sefidgaran, M.; Mirzaie, M.; Ebrahimzadeh, A. Reliability model of the power transformer with $\{\mathrm{ONAF}\}$ cooling. Int. J. Electr. Power Energy Syst. 2012, 35, 97-104. [CrossRef]

24. Sun, R.; Singh, C.; Cheng, L.; Sun, Y. Short-term reliability evaluation using control variable based dagger sampling method. Electr. Power Syst. Res. 2010, 80, 682-689. [CrossRef]

25. Pindoriya, N.M.; Jirutitijaroen, P.; Srinivasan, D.; Singh, C. Composite Reliability Evaluation Using Monte Carlo Simulation and Least Squares Support Vector Classifier. IEEE Trans. Power Syst. 2011, 26, 2483-2490. [CrossRef]

26. Dorostkar-Ghamsari, M.; Fotuhi-Firuzabad, M.; Aminifar, F.; Safdarian, A.; Lehtonen, M. Optimal distributed static series compensator placement for enhancing power system loadability and reliability. IET Gener. Transm. Distrib. 2015, 9, 1043-1050. [CrossRef]

27. Mosadeghy, M.; Yan, R.; Saha, T.K. A Time-Dependent Approach to Evaluate Capacity Value of Wind and Solar PV Generation. IEEE Trans. Sustain. Energy 2016, 7, 129-138. [CrossRef]

28. Benidris, M.; Mitra, J. Reliability and sensitivity analysis of composite power systems considering voltage and reactive power constraints. IET Gener. Transm. Distrib. 2015, 9, 1245-1253. [CrossRef]

29. Wang, J.; Zobaa, A.F.; Huang, C.; Chen, C. Day-ahead allocation of operation reserve in composite power systems with large-scale centralized wind farms. J. Mod. Power Syst. Clean Energy 2016, 4, 238-247. [CrossRef]

30. Sulaeman, S.; Tian, Y.; Benidris, M.; Mitra, J. Quantification of Storage Necessary to Firm Up Wind Generation. IEEE Trans. Ind. Appl. 2017, 53, 3228-3236. [CrossRef]

31. Gu, Y.; McCalley, J.D.; Ni, M. Coordinating Large-Scale Wind Integration and Transmission Planning. IEEE Trans. Sustain. Energy 2012, 3, 652-659. [CrossRef]

32. Ghofrani, M.; Arabali, A.; Etezadi-Amoli, M.; Fadali, M.S. Energy Storage Application for Performance Enhancement of Wind Integration. IEEE Trans. Power Syst. 2013, 28, 4803-4811. [CrossRef]

33. He, J.; Sun, Y.; Kirschen, D.S.; Singh, C.; Cheng, L. State-space partitioning method for composite power system reliability assessment. IET Gener. Transm. Distrib. 2010, 4, 780-792. [CrossRef]

34. Goel, L.; Low, L.S. Incorporating generator scheduling in composite power system well-being analysis. In Proceedings of the 2001 IEEE Power Tech Proceedings, Porto, Portugal, 10-13 September 2001; Volume 3, p. 6.

35. Nel, W.P.; Cooper, C.J. Implications of fossil fuel constraints on economic growth and global warming. Energy Policy 2009, 37, 166-180. [CrossRef]

36. Lund, H. Renewable energy strategies for sustainable development. Energy 2007, 32, 912-919. [CrossRef]

37. Jones, L.E. Renewable Energy Integration: Practical Management of Variability, Uncertainty, and Flexibility in Power Grids; Academic Press: Cambridge, MA, USA, 2017.

38. Abunima, H.; Jabir, H.; Teh, J. An Investigation of Reactive-Active Power Control approach for Grid-Connected PV Arrays in A Low Voltage Distribution System. In 10th International Conference on Robotics, Vision, Signal Processing \& Power Applications; Springer: Penang, Malaysia, 2018. 
39. Zhang, P.; Li, W.; Li, S.; Wang, Y.; Xiao, W. Reliability assessment of photovoltaic power systems: Review of current status and future perspectives. Appl. Energy 2013, 104, 822-833. [CrossRef]

40. Ou, T.-C.; Lu, K.-H.; Huang, C.-J. Improvement of transient stability in a hybrid power multi-system using a designed NIDC (Novel Intelligent Damping Controller). Energies 2017, 10, 488. [CrossRef]

41. Dasgupta, S.; Sahoo, S.K.; Panda, S.K. Single-phase inverter control techniques for interfacing renewable energy sources with microgrid-Part I: Parallel-connected inverter topology with active and reactive power flow control along with grid current shaping. IEEE Trans. Power Electron. 2011, 26, 717-731. [CrossRef]

42. Suberu, M.Y.; Mustafa, M.W.; Bashir, N. Energy storage systems for renewable energy power sector integration and mitigation of intermittency. Renew. Sustain. Energy Rev. 2014, 35, 499-514. [CrossRef]

43. Billinton, R.; Singh, G. Application of adverse and extreme adverse weather: Modelling in transmission and distribution system reliability evaluation. IEE Proc. Gener. Transm. Distrib. 2006, 153, 115-120. [CrossRef]

44. Mehrtash, A.; Wang, P.; Goel, L. Reliability evaluation of generation system incorporating renewable generators in a spot power market. In Proceedings of the 2011 IEEE Power and Energy Society General Meeting, Detroit, MI, USA, 24-29 July 2011; pp. 1-6.

45. Da Silva, A.M.L.; Manso, L.A.F.; Flávio, S.A.; da Rosa, M.A.; Resende, L.C. Composite reliability assessment of power systems with large penetration of renewable sources. In Reliability and Risk Evaluation of Wind Integrated Power Systems; Springer: Berlin/Heidelberg, Germany, 2013; pp. 107-128.

46. Gungor, V.C.; Lu, B.; Hancke, G.P. Opportunities and challenges of wireless sensor networks in smart grid. IEEE Trans. Ind. Electron. 2010, 57, 3557-3564. [CrossRef]

47. Jabir, H.J.; Teh, J.; Ishak, D.; Abunima, H. Impact of Demand-Side Management on the Reliability of Generation Systems. Energies 2018, 11, 2155. [CrossRef]

48. Huang, D.; Billinton, R. Effects of Load Sector Demand Side Management Applications in Generating Capacity Adequacy Assessment. IEEE Trans. Power Syst. 2012, 27, 335-343. [CrossRef]

49. Diewvilai, R.; Nidhiritdhikrai, R.; Eua-arporn, B. Demand side management worth evaluation under generation system planning framework. In Proceedings of the 9th International Conference on Electrical Engineering/Electronics, Computer, Telecommunications and Information Technology (ECTI-CON), Phetchaburi, Thailand, 16-18 May 2012; pp. 1-4.

50. Teh, J.; Cotton, I. Risk assessment of dynamic thermal rating system. In Proceedings of the IET International Conference on Resilience of Transmission and Distribution Networks (RTDN), Birmingham, UK, 22-24 September 2015; pp. 1-6.

51. Rahim, A.A.; Abidin, I.Z.; Tarlochan, F.; Hashim, M.F. Thermal rating monitoring of the TNB overhead transmission line using line ground clearance measurement and weather monitoring techniques. In Proceedings of the 2010 4th International Power Engineering and Optimization Conference (PEOCO), Shah Alam, Malaysia, 23-24 June 2010; pp. 274-280.

52. Teh, J.; Lai, C.-M.; Cheng, Y.-H. Composite reliability evaluation for transmission network planning. AIMS Energy 2018, 6, 170-186. [CrossRef]

53. Zamora, R.; Srivastava, A.K. Controls for microgrids with storage: Review, challenges, and research needs. Renew. Sustain. Energy Rev. 2010, 14, 2009-2018. [CrossRef]

54. Ilo, A. "Link"-The smart grid paradigm for a secure decentralized operation architecture. Electr. Power Syst. Res. 2016, 131, 116-125. [CrossRef]

55. Kaur, A.; Kaushal, J.; Basak, P. A review on microgrid central controller. Renew. Sustain. Energy Rev. 2016, 55, 338-345. [CrossRef]

56. Ou, T.-C. Ground fault current analysis with a direct building algorithm for microgrid distribution. Int. J. Electr. Power Energy Syst. 2013, 53, 867-875. [CrossRef]

57. Ou, T.-C.; Hong, C.-M. Dynamic operation and control of microgrid hybrid power systems. Energy 2014, 66, 314-323. [CrossRef]

58. Ou, T.-C. A novel unsymmetrical faults analysis for microgrid distribution systems. Int. J. Electr. Power Energy Syst. 2012, 43, 1017-1024. [CrossRef]

59. Ravindranath, B.; Chander, M. Power System Protection and Switchgear; New Age International: New Delhi, India, 1977.

60. Prasad, A.; Edward, J.B. Application of wavelet technique for fault classification in transmission systems. Procedia Comput. Sci. 2016, 92, 78-83. [CrossRef] 
61. Khaitan, S.K.; Gupta, A. High Performance Computing in Power and Energy Systems; Springer: Berlin/Heidelberg, Germany, 2012.

62. Seifi, H.; Sepasian, M.S. Electric Power System Planning: Issues, Algorithms and Solutions; Springer Science \& Business Media: Berlin/Heidelberg, Germany, 2011.

63. Chatterjee, D.; Webb, J.; Gao, Q.; Vaiman, M.Y.; Vaiman, M.M.; Povolotskiy, M. N-1-1 AC contingency analysis as a part of NERC compliance studies at midwest ISO. In Proceedings of the 2010 IEEE PES Transmission and Distribution Conference and Exposition, New Orleans, LA, USA, 19-22 April 2010; pp. 1-7.

64. Yas, Q.M.; Zaidan, A.A.; Zaidan, B.B.; Hashim, M.; Lim, C.K. A systematic review on smartphone skin Cancer apps: Coherent taxonomy, motivations, open challenges and recommendations, and new research direction. J. Circuits Syst. Comput. 2018, 27, 1830003. [CrossRef]

65. Wang, Y.; Guo, C.; Wu, Q.; Dong, S. Adaptive sequential importance sampling technique for short-term composite power system adequacy evaluation. IET Gener. Transm. Distrib. 2014, 8, 730-741. [CrossRef]

66. Miryousefi Aval, S.M.; Ahadi, A.; Hayati, H. A novel method for reliability and risk evaluation of wind energy conversion systems considering wind speed correlation. Front. Energy 2016, 10, 46-56. [CrossRef]

67. Zhang, Y.; Chowdhury, A.A.; Koval, D.O. Probabilistic Wind Energy Modeling in Electric Generation System Reliability Assessment. IEEE Trans. Ind. Appl. 2011, 47, 1507-1514. [CrossRef]

68. Salehi-Dobakhshari, A.; Fotuhi-Firuzabad, M. Integration of large-scale wind farm projects including system reliability analysis. IET Renew. Power Gener. 2011, 5, 89-98. [CrossRef]

69. Huang, D.; Billinton, R. Effects of Wind Power on Bulk System Adequacy Evaluation Using the Well-Being Analysis Framework. IEEE Trans. Power Syst. 2009, 24, 1232-1240. [CrossRef]

70. De Magalhaes Carvalho, L.; da Rosa, M.A.; da Silva, A.M.L.; Miranda, V. Probabilistic Analysis for Maximizing the Grid Integration of Wind Power Generation. IEEE Trans. Power Syst. 2012, 27, 2323-2331. [CrossRef]

71. Zadkhast, S.; Fotuhi-Firuzabad, M.; Aminifar, F.; Billinton, R.; Faried, S.O.; Edris, A.A. Reliability Evaluation of an HVDC Transmission System Tapped by a VSC Station. IEEE Trans. Power Deliv. 2010, 25, 1962-1970. [CrossRef]

72. Zhao, S.; Singh, C. Studying the Reliability Implications of Line Switching Operations. IEEE Trans. Power Syst. 2017, 32, 4614-4625. [CrossRef]

73. Moghadasi, S.M.; Kazemi, A.; Fotuhi-Firuzabad, M.; Edris, A.A. Composite System Reliability Assessment Incorporating an Interline Power-Flow Controller. IEEE Trans. Power Deliv. 2008, 23, 1191-1199. [CrossRef]

74. Dorostkar-Ghamsari, M.; Fotuhi-Firuzabad, M.; Aminifar, F. Probabilistic Worth Assessment of Distributed Static Series Compensators. IEEE Trans. Power Deliv. 2011, 26, 1734-1743. [CrossRef]

75. Shaker, H.; Zareipour, H.; Fotuhi-Firuzabad, M. Reliability Modeling of Dynamic Thermal Rating. IEEE Trans. Power Deliv. 2013, 28, 1600-1609. [CrossRef]

76. Zhang, Y.; Xiang, Y.; Wang, L. Power System Reliability Assessment Incorporating Cyber Attacks Against Wind Farm Energy Management Systems. IEEE Trans. Smart Grid 2017, 8, 2343-2357. [CrossRef]

77. Lei, H.; Singh, C. Non-Sequential Monte Carlo Simulation for Cyber-Induced Dependent Failures in Composite Power System Reliability Evaluation. IEEE Trans. Power Syst. 2017, 32, 1064-1072. [CrossRef]

78. Lei, H.; Singh, C. Power system reliability evaluation considering cyber-malfunctions in substations. Electr. Power Syst. Res. 2015, 129, 160-169. [CrossRef]

79. Aminifar, F.; Fotuhi-Firuzabad, M.; Shahidehpour, M.; Safdarian, A. Impact of WAMS Malfunction on Power System Reliability Assessment. IEEE Trans. Smart Grid 2012, 3, 1302-1309. [CrossRef]

80. Liu, Y.; Singh, C. A Methodology for Evaluation of Hurricane Impact on Composite Power System Reliability. IEEE Trans. Power Syst. 2011, 26, 145-152. [CrossRef]

81. Benidris, M.; Mitra, J. Reliability and Sensitivity Analysis of Composite Power Systems Under Emission Constraints. IEEE Trans. Power Syst. 2014, 29, 404-412. [CrossRef]

82. Billinton, R.; Huang, D. Effects of load forecast uncertainty on bulk electric system reliability evaluation. IEEE Trans. Power Syst. 2008, 23, 418-425. [CrossRef]

83. Lei, H.; Singh, C.; Sprintson, A. Reliability Modeling and Analysis of IEC 61850 Based Substation Protection Systems. IEEE Trans. Smart Grid 2014, 5, 2194-2202. [CrossRef]

84. Eliassi, M.; Seifi, H.; Haghifam, M.R. Incorporation of protection system failures into bulk power system reliability assessment by Bayesian networks. IET Gener. Transm. Distrib. 2015, 9, 1226-1234. [CrossRef] 
85. Li, W.; Zhou, J.; Xie, K.; Xiong, X. Power System Risk Assessment Using a Hybrid Method of Fuzzy Set and Monte Carlo Simulation. IEEE Trans. Power Syst. 2008, 23, 336-343.

86. Moshari, A.; Ebrahimi, A.; Fotuhi-Firuzabad, M. Short-Term Impacts of DR Programs on Reliability of Wind Integrated Power Systems Considering Demand-Side Uncertainties. IEEE Trans. Power Syst. 2016, 31, 2481-2490. [CrossRef]

87. Choi, J.; Lim, J.; Lee, K.Y. DSM Considered Probabilistic Reliability Evaluation and an Information System for Power Systems Including Wind Turbine Generators. IEEE Trans. Smart Grid 2013, 4, 425-432. [CrossRef]

88. Lopes, V.S.; Borges, C.L.T. Impact of the Combined Integration of Wind Generation and Small Hydropower Plants on the System Reliability. IEEE Trans. Sustain. Energy 2015, 6, 1169-1177. [CrossRef]

89. Borges, C.L.T.; Dias, J.A.S. A Model to Represent Correlated Time Series in Reliability Evaluation by Non-Sequential Monte Carlo Simulation. IEEE Trans. Power Syst. 2017, 32, 1511-1519. [CrossRef]

90. Mehrtash, A.; Wang, P.; Goel, L. Reliability evaluation of restructured power systems using a novel optimal power-flow-based approach. IET Gener. Transm. Distrib. 2013, 7, 192-199. [CrossRef]

91. Qin, Z.; Li, W.; Xiong, X. Incorporating multiple correlations among wind speeds, photovoltaic powers and bus loads in composite system reliability evaluation. Appl. Energy 2013, 110, 285-294. [CrossRef]

92. Xu, Y.; Singh, C. Power System Reliability Impact of Energy Storage Integration With Intelligent Operation Strategy. IEEE Trans. Smart Grid 2014, 5, 1129-1137. [CrossRef]

93. Teh, J.; Cotton, I. Reliability Impact of Dynamic Thermal Rating System in Wind Power Integrated Network. IEEE Trans. Reliab. 2016, 65, 1081-1089. [CrossRef]

94. Rei, A.M.; Schilling, M.T. Reliability Assessment of the Brazilian Power System Using Enumeration and Monte Carlo. IEEE Trans. Power Syst. 2008, 23, 1480-1487. [CrossRef]

95. Edimu, M.; Gaunt, C.T.; Herman, R. Using probability distribution functions in reliability analyses. Electr. Power Syst. Res. 2011, 81, 915-921. [CrossRef]

96. Benidris, M.; Mitra, J.; Singh, C. Integrated Evaluation of Reliability and Stability of Power Systems. IEEE Trans. Power Syst. 2017, 32, 4131-4139. [CrossRef]

97. Hamoud, G.A. Assessment of Spare Breaker Requirements for High Voltage Transmission Stations. IEEE Trans. Power Syst. 2013, 28, 4789-4795. [CrossRef]

98. Da Silva, A.M.L.; Jardim, J.L.; de Lima, L.R.; Machado, Z.S. A Method for Ranking Critical Nodes in Power Networks Including Load Uncertainties. IEEE Trans. Power Syst. 2016, 31, 1341-1349. [CrossRef]

99. Setreus, J.; Hilber, P.; Arnborg, S.; Taylor, N. Identifying Critical Components for Transmission System Reliability. IEEE Trans. Power Syst. 2012, 27, 2106-2115. [CrossRef]

100. Akhavein, A.; Firuzabad, M.F. A heuristic-based approach for reliability importance assessment of energy producers. Energy Policy 2011, 39, 1562-1568. [CrossRef]

101. Rajabi-Ghahnavieh, A.; Fotuhi-Firuzabad, M.; Shahidehpour, M.; Feuillet, R. UPFC for Enhancing Power System Reliability. IEEE Trans. Power Deliv. 2010, 25, 2881-2890. [CrossRef]

102. Baboli, P.T.; Moghaddam, M.P. Allocation of Network-Driven Load-Management Measures Using Multiattribute Decision Making. IEEE Trans. Power Deliv. 2010, 25, 1839-1845. [CrossRef]

103. Jaefari-Nokandi, M.; Monsef, H. Scheduling of Spinning Reserve Considering Customer Choice on Reliability. IEEE Trans. Power Syst. 2009, 24, 1780-1789. [CrossRef]

104. Da Silva, A.M.L.; Castro, J.F.C.; González-Fernández, R.A. Spinning Reserve Assessment Under Transmission Constraints Based on Cross-Entropy Method. IEEE Trans. Power Syst. 2016, 31, 1624-1632. [CrossRef]

105. Billinton, R.; Gao, Y.; Karki, R. Application of a Joint Deterministic-Probabilistic Criterion to Wind Integrated Bulk Power System Planning. IEEE Trans. Power Syst. 2010, 25, 1384-1392. [CrossRef]

106. Castro, M.; Pudjianto, D.; Djapic, P.; Strbac, G. Reliability-driven transmission investment in systems with wind generation. IET Gener. Transm. Distrib. 2011, 5, 850-859. [CrossRef]

107. Da Silva, A.M.L.; Manso, L.A.d.F.; Sales, W.d.S.; Flavio, S.A.; Anders, G.J.; de Resende, L.C. Chronological Power Flow for Planning Transmission Systems Considering Intermittent Sources. IEEE Trans. Power Syst. 2012, 27, 2314-2322. [CrossRef]

108. Yang, F.; Chang, C.S. Multiobjective Evolutionary Optimization of Maintenance Schedules and Extents for Composite Power Systems. IEEE Trans. Power Syst. 2009, 24, 1694-1702. [CrossRef]

109. Yang, F.; Chang, C.S. Optimisation of maintenance schedules and extents for composite power systems using multi-objective evolutionary algorithm. IET Gener. Transm. Distrib. 2009, 3, 930-940. [CrossRef] 
110. Abbasghorbani, M.; Mashhadi, H.R. Circuit breakers maintenance planning for composite power systems. IET Gener. Transm. Distrib. 2013, 7, 1135-1143. [CrossRef]

111. Ghorani, R.; Fotuhi-Firuzabad, M.; Dehghanian, P.; Li, W. Identifying critical components for reliability centred maintenance management of deregulated power systems. IET Gener. Transm. Distrib. 2015, 9, 828-837. [CrossRef]

112. Awadallah, S.K.E.; Milanović, J.V.; Jarman, P.N. Reliability Based Framework for Cost-Effective Replacement of Power Transmission Equipment. IEEE Trans. Power Syst. 2014, 29, 2549-2557. [CrossRef]

113. Rajabi-Ghahnavieh, A.; Fotuhi-Firuzabad, M.; Shahidehpour, M.; Feuillet, R. Optimal Allocation of Available Transfer Capability in Operating Horizon. IEEE Trans. Power Syst. 2009, 24, 967-975. [CrossRef]

114. Zhang, Y.; Zhu, S.; Chowdhury, A.A. Reliability Modeling and Control Schemes of Composite Energy Storage and Wind Generation System With Adequate Transmission Upgrades. IEEE Trans. Sustain. Energy 2011, 2, 520-526. [CrossRef]

115. Lami, B.; Bhattacharya, K. Clustering Technique Applied to Nodal Reliability Indices for Optimal Planning of Energy Resources. IEEE Trans. Power Syst. 2016, 31, 4679-4690. [CrossRef]

116. Jadidoleslam, M.; Ebrahimi, A.; Latify, M.A. Probabilistic transmission expansion planning to maximize the integration of wind power. Renew. Energy 2017, 114, 866-878. [CrossRef]

117. Javadi, M.S.; Saniei, M.; Mashhadi, H.R.; Gutierrez-Alcaraz, G. Multi-objective expansion planning approach: Distant wind farms and limited energy resources integration. IET Renew. Power Gener. 2013, 7, 652-668. [CrossRef]

118. Moeini-Aghtaie, M.; Abbaspour, A.; Fotuhi-Firuzabad, M. Incorporating Large-Scale Distant Wind Farms in Probabilistic Transmission Expansion Planning-Part I: Theory and Algorithm. IEEE Trans. Power Syst. 2012, 27, 1585-1593. [CrossRef]

119. Choi, J.; Park, J.; Cho, K.; Jeon, D.; Cha, J.; Lee, H.; Lee, K.Y. Reliability-Based Grid Expansion Planning of Power Systems Considering Wind Turbine Generators. IFAC Proc. Vol. 2011, 44, 11701-11706. [CrossRef]

120. Alizadeh, B.; Jadid, S. A dynamic model for coordination of generation and transmission expansion planning in power systems. Int. J. Electr. Power Energy Syst. 2015, 65, 408-418. [CrossRef]

121. Moshari, A.; Ebrahimi, A. Reliability-based nodal evaluation and prioritization of demand response programs. Int. Trans. Electr. Energy Syst. 2015, 25, 3384-3407. [CrossRef]

122. Javadi, M.S.; Saniei, M.; Mashhadi, H.R. An augmented NSGA-II technique with virtual database to solve the composite generation and transmission expansion planning problem. J. Exp. Theor. Artif. Intell. 2014, 26, 211-234. [CrossRef]

123. Da Silva, A.L.; Resende, L.C.D.; da Fonseca Manso, L.A.; Miranda, V. Well-being analysis for composite generation and transmission systems based on pattern recognition techniques. IET Gener. Transm. Distrib. 2008, 2, 202-208. [CrossRef]

124. Hong, Y.-Y.; Lee, L.-H. Reliability assessment of generation and transmission systems using fault-tree analysis. Energy Convers. Manag. 2009, 50, 2810-2817. [CrossRef]

125. Green, R.C.; Wang, L.; Alam, M.; Singh, C. Intelligent state space pruning for Monte Carlo simulation with applications in composite power system reliability. Eng. Appl. Artif. Intell. 2013, 26, 1707-1724. [CrossRef]

126. Benidris, M.; Elsaiah, S.; Mitra, J. Power system reliability evaluation using a state space classification technique and particle swarm optimisation search method. IET Gener. Transm. Distrib. 2015, 9, 1865-1873. [CrossRef]

127. Bordeerath, B.; Jirutitijaroen, P. Techniques for improving precision and construction efficiency of a pattern classifier in composite system reliability assessment. Electr. Power Syst. Res. 2012, 88, 33-41. [CrossRef]

128. Kumar, T.B.; Sekhar, O.C.; Ramamoorty, M. Composite power system reliability evaluation using modified minimal cut set approach. Alexandria Eng. J. 2017. [CrossRef]

129. Liu, Y.; Singh, C. Reliability Evaluation of Composite Power Systems Using Markov Cut-Set Method. IEEE Trans. Power Syst. 2010, 25, 777-785. [CrossRef]

130. Yongji, G.; Yongjian, X.; Kai, X.; Huiyi, Y. Composite system reliability evaluation based on Monte-Carlo simulation combined with outages screening. IEEE Trans. Power Syst. 1999, 14, 785-790. [CrossRef]

131. Tómasson, E.; Söder, L. Improved Importance Sampling for Reliability Evaluation of Composite Power Systems. IEEE Trans. Power Syst. 2017, 32, 2426-2434. [CrossRef]

132. Safdarian, A.; Fotuhi-Firuzabad, M.; Aminifar, F.; Lehtonen, M. A new formulation for power system reliability assessment with AC constraints. Int. J. Electr. Power Energy Syst. 2014, 56, 298-306. [CrossRef] 
133. Eliassi, M.; Dashtaki, A.K.; Seifi, H.; Haghifam, M.R.; Singh, C. Application of Bayesian networks in composite power system reliability assessment and reliability-based analysis. IET Gener. Transm. Distrib. 2015, 9, 1755-1764. [CrossRef]

134. Liu, W.; Cheng, R.; Xu, Y.; Liu, Z. Fast reliability evaluation method for composite power system based on the improved EDA and double cross linked list. IET Gener. Transm. Distrib. 2017, 11, 3835-3842. [CrossRef]

135. Chen, Q.; Mili, L. Composite Power System Vulnerability Evaluation to Cascading Failures Using Importance Sampling and Antithetic Variates. IEEE Trans. Power Syst. 2013, 28, 2321-2330. [CrossRef]

136. Hou, Y.; Wang, X.; Guo, J. Quasi Monte Carlo method for reliability evaluation of power system based on Dimension Importance Sorting. Int. Trans. Electr. Energy Syst. 2017, 27, e2264. [CrossRef]

137. Akhavein, A.; Fotuhi-Firuzabad, M.; Billinton, R.; Farokhzad, D. Adequacy equivalent development of composite generation and transmission systems using network screening. IET Gener. Transm. Distrib. 2011, 5, 1141-1148. [CrossRef]

138. Hua, B.; Bie, Z.; Liu, C.; Li, G.; Wang, X. Eliminating Redundant Line Flow Constraints in Composite System Reliability Evaluation. IEEE Trans. Power Syst. 2013, 28, 3490-3498. [CrossRef]

139. Kim, J.; Bucklew, J.A.; Dobson, I. Splitting Method for Speedy Simulation of Cascading Blackouts. IEEE Trans. Power Syst. 2013, 28, 3010-3017. [CrossRef]

140. Hua, B.; Bie, Z.; Au, S.-K.; Li, W.; Wang, X. Extracting Rare Failure Events in Composite System Reliability Evaluation Via Subset Simulation. IEEE Trans. Power Syst. 2015, 30, 753-762. [CrossRef]

141. Akhavein, A.; Porkar, B. A composite generation and transmission reliability test system for research purposes. Renew. Sustain. Energy Rev. 2017, 75, 331-337. [CrossRef]

142. Akhavein, A.; Firuzabad, M.F.; Billinton, R.; Farokhzad, D. Review of reduction techniques in the determination of composite system adequacy equivalents. Electr. Power Syst. Res. 2010, 80, 1385-1393. [CrossRef]

143. Billinton, R.; Karki, R.; Gao, Y.; Huang, D.; Hu, P.; Wangdee, W. Adequacy Assessment Considerations in Wind Integrated Power Systems. IEEE Trans. Power Syst. 2012, 27, 2297-2305. [CrossRef]

144. González-Fernández, R.A.; da Silva, A.M.L.; Resende, L.C.; Schilling, M.T. Composite Systems Reliability Evaluation Based on Monte Carlo Simulation and Cross-Entropy Methods. IEEE Trans. Power Syst. 2013, 28, 4598-4606. [CrossRef]

145. Billinton, R. IEEE Reliability Test System. IEEE Trans. Power Appar. Syst. 1979, PAS-98, 2047-2054. [CrossRef]

146. Billinton, R.; Kumar, S.; Chowdhury, N.; Chu, K.; Goel, L.; Khan, E.; Kos, P.; Nourbakhsh, G.; Oteng-Adjei, J. A reliability test system for educational purposes-basic results. IEEE Trans. Power Syst. 1990, 5, 319-325. [CrossRef]

147. Xia, Y.; Wan, H.; Huang, Y.; Xu, C. Stochastic modeling and quality evaluation of component-based software systems. In Proceedings of the Sixth International Conference on Quality Software (QSIC 2006), Beijing, China, 27-28 October 2006; pp. 377-384.

148. Sridhar, S.; Hahn, A.; Govindarasu, M. Cyber Physical System Security for the Electric Power Grid. Proc. IEEE 2012, 100, 210-224. [CrossRef]

149. He, J.; Cheng, L.; Kirschen, D.S.; Sun, Y. Optimising the balance between security and economy on a probabilistic basis. IET Gener. Transm. Distrib. 2010, 4, 1275-1287. [CrossRef]

150. Choi, J.; Tran, T.; El-Keib, A.A.; Thomas, R.; Oh, H.; Billinton, R. A method for transmission system expansion planning considering probabilistic reliability criteria. IEEE Trans. Power Syst. 2005, 20, 1606-1615. [CrossRef]

151. Gaun, A.; Rechberger, G.; Renner, H.; Lehtonen, M. Enumeration based reliability assessment algorithm considering nodal uncertainties. In Proceedings of the 2010 IEEE Power and Energy Society General Meeting, Minneapolis, MN, USA, 25-29 July 2010; pp. 1-8.

152. Karki, R.; Hu, P.; Billinton, R. A simplified wind power generation model for reliability evaluation. IEEE Trans. Energy Convers. 2006, 21, 533-540. [CrossRef]

153. Koval, D.O.; Chowdhury, A.A. Assessment of Transmission-Line Common-Mode, Station-Originated, and Fault-Type Forced-Outage Rates. IEEE Trans. Ind. Appl. 2010, 46, 313-318. [CrossRef]

(C) 2018 by the authors. Licensee MDPI, Basel, Switzerland. This article is an open access article distributed under the terms and conditions of the Creative Commons Attribution (CC BY) license (http://creativecommons.org/licenses/by/4.0/). 